\section{SPENDER, LA GUERRA \\ DE ESPAÑA Y LOS LÍMITES \\ DE LA AUTOBIOGRAFÍA}

\author{
Gabriel Insausti \\ Departamento de Literatura \\ Universidad de Navarra
}

\section{SPENDER, THE SPANISH WAR AND THE BOUNDARIES OF AUTOBIOGRAPHY}

\begin{abstract}
During the thirties, the poet Stephen Spender slowly approached Marxist ideals and eventually, in the first days of Jan 1937, joined the Communist Party, which he quit after his experience in the Spanish war. With the story of his conversion to Marxism and his violent incantation, Spender's autobiography World within a World broaches, among several topics, a set of fundamental questions concerning the limits of autobiography and the nature of autobiographical writing.
\end{abstract}

KEY WORDS: Autobiography; Marxism; Spanish war; sacrifice culture; political disappointment.

\section{Una tarde en Venecia}

En el primer capitulo de su autobiografía, The Buried Day, Cecil Day Lewis recordaba una conversación entre él y Auden en Venecia, mientras bebían un vaso de grappa junto al Gran Canal:

- ¿Sabías que X (un amigo de nosotros, un poeta que se encontraba también en Venecia en aquel momento) estaba escribiendo su autobiografía?

-Sí.

- Bueno, y ¿por qué no lo detuviste?

- ¿Cómo podía?

- Sabes perfectamente, Cecil, que ningún poeta debería escribir nunca su autobiografía.

$-O h$.

- ¿La ha traído consigo?

- Probablemente.

- Entonces iremos y la quemaremos (Lewis 1960, 25)'.
RESUMEN: Durante los años treinta el poeta Stephen Spender fue aproximándose paulatinamente al ideario marxista, al que se adhirió a principios de 1937 con su militancia en el Partido Comunista, que abandonaría tras sus experiencias en la Guerra Civil española. Con el relato de su conversión al marxismo en los años treinta y su posterior y violenta retractación, la autobiografía de Spender World within a World plantea, entre otras cosas, una serie de cuestiones fundamentales sobre los límites de la autobiografía y sobre la naturaleza de esa escritura.

PALABRAS CLAVE: Autobiografía; marxismo; Guerra Civil española; cultura sacrificial; desencanto ideológico.

No es necesario hacer muchas cábalas para adivinar que se trata del congreso del Pen Club de 1949 y que bajo el anonimato de $X$ se esconde el rostro de Spender, que el año anterior había comenzado a escribir su autobiografía durante un viaje de varios meses por Estados Unidos. Y, si bien Auden no aclara en el relato de Day Lewis las razones por las que es anatema el vate que se convierta en autobiógrafo, en una de esas "certezas" tajantes por las que tan admirado fue entre sus amigos, no resulta difícil entrever una explicación literaria en su decidido objetivismo y su rechazo del discurso testimonial. A sus ojos, al tomar la propia materia de su vida como tema, al situarse en el centro, Spender incurría en una suerte de impudor, el ejercicio de pornografía anímica propio de quien desvela lo que sólo debe decirse entre susurros y a unos pocos allegados.

De hecho, no le faltaba razón a Auden: en "Confessions and Autobiography" Spender propondría ese impudor como requisito del relato autobiográfico, pero al mismo 
tiempo eludiría toda inmediación ingenua y advertiría de que en último término todo relato supone un constructo: su autobiógrafo predilecto, explicaría también, era el "indiscreto, egomaníaco, inmoral, exhibicionista, pornógrafo", que elude los pormenores sobre la familia y la época y entra de lleno en "la experiencia de ser él mismo", con el único criterio de que debe contar "la verdad desnuda", aunque señalaría también que "normalmente su verdad es desnuda aunque no sea del todo verdadera" (1980, 118). Su queja es precisamente que abundan las autoficciones como las de Sassoon y escasean autobiografías como las de Gide o Henry Miller, que ponen a prueba "la capacidad del ser humano de decir la verdad sobre sí mismo" $(1980,121)$. En último término, su modelo parece ser Rousseau: el autobiógrafo movido por la voluntad de montrer á mes semblables un homme dans toute la vérité de la nature.

Casi cincuenta años después de esa escena escrita en los márgenes de la Historia de Venecia, como un efímero reflejo sobre sus aguas, un Spender octogenario cerraba el último capitulo de esa vida con una notoriedad que trajo consigo nuevas manifestaciones de impudor. Por aquel entonces yo vivía en Cambridge y pude comprobar cómo durante unos días el anciano poeta recuperaba cierta actualidad, cómo los puestos de libros de Market Square - paperback los martes, hardback los jueves- se inundaban con viejas ediciones de sus ensayos y libros de poemas y cómo los obituarios esbozaban una suerte de recapitulación crítica de su figura: Christopher Hitchens le reprochaba en The Atlantic que habia pasado más tiempo "siendo" un poeta que escribiendo poesía; Peter Poster recordaba en The Lamp, más que sus libros, la presencia de su alta figura en todos los acontecimientos literarios; Eric Page se mostraba un poco más respetuoso en el New York Times y elogiaba especialmente los escritos del difunto sobre la relación entre el artista y la política; y Ted Hughes esbozaba un rendido elogio en Index on Censhorship. De hecho, Spender había recobrado una momentánea actualidad apenas año y medio antes, y por razones a las que Hughes -entonces el poeta laureado de Inglaterra, pero siempre perseguido por la sombra de Sylvia Plath- era especialmente sensible: el escritor norteamericano David Leavitt había publicado la novela While England Sleeps, en la que entre otras cosas aireaba la relación homosexual de Spender con Tony Hyndman sesenta años atrás y Spender había protestado, no exactamente por hacerse pública una historia que los lectores conocían por su propia pluma desde la publicación de World within a World en 1951, sino por lo que a su juicio era una distorsión de la realidad. El episodio terminó en los tribunales, todas las copias de la edición original fueron destruidas y se publicó una nueva versión aprobada por Spender.

Creo que esta aprobación constituye un acto de naturaleza literaria, además de jurídica. Spender ya había puesto a prueba su propia capacidad de "decir la verdad sobre si mismo", y sería interesante dilucidar si su disgusto se debía a que el libro de Leavitt contradecía los hechos o más bien su propio relato en World within a World, donde el poeta había dado los detalles de su relación con Tony. Porque en Spender encuentra su realización perfecta el escritor para quien su leyenda personal constituye el bien más preciado, alguien para quien la escritura es una forma de acción y la acción una incoación a la escritura, en la que todo cuaja, se ordena y cobra sentido. $Y$ ese grado extremo de autoconciencia se muestra a las claras en la reticencia a conceder esa aprobación, que no tuvo lugar en los estudios autobiográficos de David Leeming (Stephen Spender: A Life in Modernism) y Hugh David (Stephen Spender: A Portrait with Background) y que sólo llegaria con el exhaustivo trabajo de Jon Sutherland, Stephen Spender: The Authorized Biography, que en su título mismo exhibía complacida el marchamo del nihil obstat.

Es más, puede decirse que esa cuidadosa gestación de su leyenda personal impregna casi todos los escritos del propio Spender. En otras palabras, toda su obra literaria es en gran medida autobiográfica: lo es, por supuesto, su autobiografía World within a World; también sus diarios, reunidos en September Journal; lo es su poesía, eminentemente lírica, recogida en varias antologías y varias ediciones de poemas completos, hasta la de 1985; lo son sus novelas The Temple y The Backward Son; lo son ensayos como The Creative Element, The Making of a Poem, The Struggle of the Modern, Love-Hate Relations y T. S. Eliot, en la medida en que en ellos se estudia la literatura de escritores de la generación de Spender o que fueron amigos de Spender o que supusieron referencias importantes para él y para su época; y lo son también libros como The Thirties and After, The Year of the Young Rebels o Citizens in War, pues en ellos se da cuenta de los acontecimientos históricos del siglo XX desde el punto de vista de la experiencia personal del autor. 
Lo fascinante del caso es que durante parte del itinerario de Spender él mismo se situó en unas coordenadas que quedaban fuera del territorio de la autobiografía, de sus condiciones de posibilidad: si se trataba de indagar en la identidad del yo, sus actitudes juveniles habian supuesto precisamente la abolición de la idea de yo. En los años treinta más que nunca, la idea pascaliana de que le moi est haissable constituía una premisa con la que el escritor británico debía contar World within a World puede, pues, leerse como una suerte de autobiografía trascendental, en el sentido kantiano, ya que desarrolla un discurso que explora sus propias condiciones de posibilidad, la existencia de su objeto como tal. Con el relato de su conversión al marxismo en los años treinta y su posterior y violenta retractación Spender plantea, entre otras cosas, una serie de cuestiones fundamentales sobre los límites de la autobiografía y sobre la naturaleza de esa escritura.

\section{THe Roaring THIRTIES}

En el primer párrafo de la introducción a World within a World, Spender adelanta que el libro trata "unos pocos temas": el amor, la poesía, la política, la vida literaria, la infancia, los viajes y el desarrollo de ciertas actitudes acerca de los problemas morales. Fundamentalmente, lo que uno encuentra en la primera parte es un retrato de familia y una presentación del niño protagonista; en la segunda, la llegada a 0xford y el trato con los que serían los poetas de la década; en la tercera, los viajes a Alemania por los que tanta afición sentirian Auden e Isherwood, la iniciación a la homosexualidad y, paralelamente, la creciente inquietud política ante el ascenso del nazismo; en la cuarta, la entrada en el Partido Comunista, los viajes a la España de la guerra, la decepción ideológica y la ruptura con su primera esposa; y en la quinta, los años de la Segunda Guerra Mundial, su servicio en la brigada antiincendios y los comienzos de lo que sería el resto de su vida literaria.

El punto de inflexión, el centro de crisis de todo el relato, se encuentra en la parte cuarta, en la que Spender se convierte casi en un epítome de su generación y refiere su decepción por la ideología comunista, que había suscitado un creciente entusiasmo durante la década. Ésta fue una de las lecturas más difundidas: por ejemplo, poco después de publicarse World within a World, Spender recibió una
Ilamada de Anthony Burgess en la que el autor de $A$ Clockwork Orange le felicitaba por haber mostrado mejor que nadie el problema de toda su generación y su actitud ante el comunismo. Esto es tanto más interesante cuanto que World within a World es una autobiografia y no unas memorias: sus páginas, sí, están repletas de referencias a Auden, Cecil Day Lewis, Louis MacNeice, Isaiah Berlin, Charles Madge, Virginia Woolf, Vanessa Bell, T. S. Eliot, Roger Fry, Christopher Isherwood, E. M. Forster, James Joyce, Cyril Connolly, Cuthbert Worsley y un largo etcétera de personalidades literarias de los años veinte, treinta y cuarenta, pero en el relato todo se encuentra supeditado a la gestación de ese universo personal, ese "mundo dentro del mundo", que constituye el individuo que firma el libro.

Así, si Burgess supo reconocer el aroma de una época fue porque Spender, ajeno a todo propósito cronístico, se había erigido en vocero de aquel conflicto ético y político desde su experiencia personal. De hecho, lo más revelador de las actitudes y los poemas de aquellos jóvenes de los treinta no se encontraba en la mayor o menor proximidad a la creciente "ortodoxia de la izquierda", sino tal vez en el drama intimo que dejaban entrever: un complejo de culpabilidad de varias caras. Este complejo se manifestaba, en primer lugar, en la caracterización del proletario como héroe y la vergüenza que comportaba una cierta conciencia de clase para el joven hombre de letras, de satinada extracción burguesa y dulce educación oxoniense. Al leer a Auden, confesaba George Barker, no podía dejar de sentir cómo le apuntaba un dedo interrogatorio, que le preguntaba por "su certificado de matrícula, su árbol genealógico y sus ingresos anuales". Así, la idea del 0xford de los años veinte que ofrece Spender en World within World es precisamente la de una comunidad dominada por la conciencia de clase y empeñada "en ignorar la proletarización de la vida europea que tenía lugar en todas partes". Este "odio de sí mismo" del escritor, que no podía ocultar su origen social privilegiado, cifraba una suerte de lucidez o clarividencia: como explicaria el poeta cuarenta años más tarde en The Thirties and After, abrir los ojos al mundo de barrios obreros, fábricas sórdidas y calles oscuras que había más allá de los salones literarios y su té con pastas equivalía al imperativo de tomar partido contra la propia clase social.

Si con el imaginario fabril y suburbial de Poems Spender se había colocado a sí mismo a un paso de esa actitud, la guerra de España no haría sino exacerbar la necesidad de 
dar ese paso: el libro que tenía entre manos en mayo, junio y julio de 1936, y que se publicaría en enero de 1937, era precisamente Forward from Liberalism, donde declaraba la insuficiencia y el agotamiento de la democracia liberal y establecía que se encontraba en una encrucijada, obligada a elegir entre la protección de las oligarquias y la sociedad sin clases. La tesis de fondo era en gran medida un producto tan epocal como el New Deal de Roosevelt: la idea de que la doctrina del laissez faire dejaba el capital en manos de unos pocos y que el Estado se veía impotente ante la iniciativa privada, con el consiguiente descontento mayoritario, en una situación que propiciaba el surgimiento de los totalitarismos e inducía a los indiferentes a aceptarlos, bajo la promesa de pan y un techo. Si se convenía en que la crisis cerraba la puerta a la via media del liberalismo, ¿cabía dudar entre los extremos del fascismo y el comunismo? ¿No era obvio que el comunismo se ofrecía como la única forma válida en aquel momento para alcanzar los fines que se proponía el liberalismo? "Soy comunista porque soy liberal", concluía Spender: el escritor debía sacrificar su origen burgués al servicio de una sociedad más justa.

Quizá este tema del sacrificio era el elemento del imaginario de la Gran Guerra que más pesaba sobre Spender y su generación. En las trincheras del frente occidental, argumentaría años más tarde $(1963,168)$ al hablar de Sassoon y Owen, "el poeta soldado se había identificado con el joven sacrificado". De hecho, con poemas como "Parable of the Old man and theYoung", su admirado Owen había subvertido el episodio bíblico del sacrificio de Isaac para denunciar el holocausto literal de las nuevas generaciones en manos de los mayores: Abraham desoía la voz del ángel y asesinaba a su hijo "y con él, uno a uno, a todos los jóvenes de Europa". Sin llegar a ese extremo, en el retrato que en World within a World esboza de la generación de su padre y su tío, tan "equilibrados" durante toda su trayectoria politica, Spender los describe en actitud impasible ante aquel "gran holocausto" de la Primera Guerra Mundial, en una denuncia implícita de la tibieza liberal. Y, como ya he comentado a propósito de Forward from Liberalism, precisamente lo que caracterizaba al liberal de 1936 era a su juicio la negativa al "sacrificio de la libertad presente individual" en aras de la igualdad futura de la Humanidad.

El rechazo de esa tibieza era para Spender y sus amigos un atractivo más del marxismo, que es preciso com- prender desde el origen pequeñoburgués de aquellos escritores. Richard Crossman lo explicaría con claridad años más tarde, pasada la marea del entusiasmo y la militancia: dentro de aquella lógica masoquista o autodestructiva, "la atracción emocional del comunismo residia precisamente en los sacrificios materiales y espirituales que exige del converso" (Crossman 1951, 14). Aquí, nuevamente, la guerra de España supuso sólo la decantación de algo que ya venía gestándose desde lejos: los sacrificios materiales iban a llegar con las muertes de algunos brigadistas, pero la predisposición a los "espirituales" había quedado más que clara durante la década. En primer lugar, como es obvio, se exigía el sacrificio de los privilegios de clase $y$, de nuevo, la idea de culpa pesaba aquí sobre la conciencia de aquellos jóvenes intelectuales. En aquel ejercicio tardío de psicoanálisis colectivo que seria "The Theme of Political Orthodoxy in the 'Thirties'", Spender se mostraria rotundo: el comunismo les proporcionó en parte una fe $y$, sobre todo, una sensación de "mala conciencia" y un deseo angustioso de aproximarse a la clase trabajadora. Si sus amores teutónicos habian ocultado aquella aspiración, todavia en los años cuarenta confesaba que el mayor interés de su trabajo en la brigada antiincendios era que le permitía "conocer por fin a los obreros".

Es evidente que bajo esa aspiración se encontraba el complejo de culpabilidad inoculado en el joven Spender por su padre, quien, como reza uno de sus versos más recordados, "no le dejaba mezclarse con los niños más duros" en el colegio. Pero es evidente también que aquel intento forzado, poco espontáneo, tenía escasos visos de ofrecer réditos literarios. En The Road to Wigan Pier Orwell habia narrado con maestría la inutilidad de este esfuerzo de adhesión una clase social ajena: "Es fácil para mí decir que quiero librarme de las distinciones de clase, pero casi todo lo que pienso y lo que hago es resultado de las distinciones de clase" (Orwell 2003, 37), reflexionaba. Algún tiempo más tarde, el propio Spender $(1951,301)$ reconocería lo que empezaba a entrever ya a finales de los treinta: que la sensibilidad burguesa del artista "difícilmente puede aspirar a adquirir por un acto de fe política una mentalidad de obrero". Inevitablemente, sus poemas sobre el mundo del proletariado, como "Moving Through the Silent Crowd" o "An Elementary School Classroom in a Slum", hablaban de aquellos hombres condenados al desempleo en una significativa tercera persona. 
Pero el sacrificio no era sólo de clase: también lo era del individuo. Como lo expresaría más tarde Robin Skelton, para aquellos jóvenes escritores Marx era Dios, pero Freud era el profeta. Y no sólo Freud: durante sus años berlineses Auden había tomado contacto con John Layard, estudioso de la psicología de W. H. Rivers, se había imbuido de aquel ambiente "psicoanalítico" que corría por la MittleEuropa de entreguerras y se había dedicado a predicar la nueva religión a sus amigos de 0xford: años más tarde, Spender y MacNeice coincidian en recordar a su amigo como una especie de psicoanalista, que en sus habitaciones del college recibía sólo visitas individuales y trataba uno por uno a sus amigos, y que empleaba constantemente una jerga pseudofreudiana. De nuevo, había aquí un vínculo con la Gran Guerra, pues Rivers habia desarrollado sus teorías en gran medida a raíz de su experiencia con los soldados traumatizados en el frente y había llegado a tratar en el hospital de Craiglockhart a Sassoon, a Graves y a Owen. Además, es preciso advertir que en Gran Bretaña el interés por el psicoanálisis no bebía exclusivamente de Viena o Berlín y que venía estrechamente asociado a la poesía: en sólo tres años se había sucedido la publicación de Unconscious (1921) y Fantasia of the Unconscious (1922), de D. H. Lawrence, de Conflict and Dream (1923), del propio Rivers, y de The Meaning of Dreams (1924), de Graves. En el tríptico final de Another Time Auden rendiría homenaje a Freud con una elegía y durante aquellos años se empeñó en casar la teoría marxista de la Historia con el psicoanálisis freudiano, salpicando sus escritos de citas de Groddeck y otros autores: según él, la llegada de la revolución social no haría sino allanar el camino a la liberación de la psique individual, lo que exigiría el concurso del psicoanalista.

Ni que decir tiene que Spender había participado en alguna medida de aquella obsesión centroeuropea, pero en su caso -como en el de algunos de sus amigos- aquel sentido de culpa que le empujaba hacia el psicoanálisis era personal y tenía muy poco que ver con el trauma de los soldados sometidos a un prolongado bombardeo. De hecho, fue precisamente la experiencia española y los problemas conyugales que sufrió en aquellos años lo que le empujó a probar el psicoanálisis, aunque sin fortuna. Pues bien, el sacrificio al que su posición ideológica le inducía lo liberaba también de sus fantasmas personales, pues la revolución debía hacerse, como él mismo expresaba, "sin tener en cuenta la suerte que pudieran correr los individuos" (Crossman 1951, 299). La instauración del nuevo orden comportaba la provisional abolición de la vida personal, y en aquel momento esa perspectiva suponía más un alivio que una constricción. Se trataba de una correlación necesaria: la exaltación de la masa era directamente proporcional a la denigración del individuo, a su desaparición como categoría real, junto con los espectros de su subconsciente. "Dónde están los violentos gestos del individuo?", preguntaba George Barker en su elocuente "Resolution of Dependence": subvirtiendo el título de Wordsworth, lo que el nuevo estado de conciencia ponía de manifiesto era que el sueño de la autarquía individual era imposible. "Debemos amarnos los unos a los otros o morir", escribía Auden en su archicomentado verso de "September 1, 1939". Todos estaban en el mismo barco, todos dependían unos de otros, y la proximidad de la guerra sólo venía a mostrar a las claras lo que Spender sabía ya desde hacía años. A principios de los cincuenta recordaba, como grabada a fuego en su memoria, una conversación que había mantenido en Berlín con Edward Upward, el Chalmers de Lions and Shadows: cuando expuso su deseo de que los cambios revolucionarios se conciliasen con la preservación de la libertad individual, Upward se quitó la pipa de la boca y dijo, sonriendo: "Gandhi". Aquella sola palabra bastó a Spender para hacerle caer en la cuenta de su idealismo imposible, de la necesidad histórica de sacrificar al individuo y permitir que su persona se convirtiera "en materia prima para uso de la maquinaria del Partido", como escribiria en The God that Failed.

Además, el sacrificio no se refería tan sólo a la clase social y a la realidad concreta individual, sino también a un instrumento tan radicalmente inherente al individuo en la cultura liberal burguesa como el ejercicio de la crítica. Si se deseaba coadyuvar al advenimiento de aquel estadio suprahistórico de la Humanidad, era preciso proceder a una especie de "cancelación de la experiencia", un ciego acto de fe que pasara por alto las imperfecciones del presente con las miras puestas en la promesa de aquella suprema bondad futura. "Nunca ha dejado de sorprenderme -escribiría Spender en World within a World $(1951,21)-$ hasta qué punto los comunistas son indiferentes a los hechos inconvenientes". Así, el hegeliano "¡Peor para la realidad!" permitía al comunista ortodoxo del momento hacer la vista gorda ante cualquier acontecimiento que desdijese de la doctrina. Un ejercicio de cinismo del que la Guerra de España proporcionaría a Spender numerosos ejemplos, como el de un corresponsal con el que entabló conversación en 
Valencia y que le reconoció que algunos de los hechos que había denunciado en sus artículos del New Statesman eran ciertos, pero que "lo importante es escribir cosas que sirvan a los fines del comunismo".

Lo fascinante y revelador de esta lógica sacrificial era que aquella indiferencia "incluso resultaba atractiva", como admitía el poeta. En la adhesión incondicional, en el inmaculado sometimiento a la ortodoxia, en la claudicación de la razón crítica, había algo de admirable y grandioso, una via rationaliter negativa que permitía al intelectual fundirse con su ideología. Era casi una actitud religiosa: siempre que conocía a un comunista, había dicho pocos años antes Spender, tenía la impresión de que era "un tipo muy alto", y viniendo de alguien que medía un metro noventa eso quería decir mucho. De este modo, al afiliarse al Partido, esperaba eludir toda vacilación e investirse de una suerte de presunción de infalibilidad, pues a él también se le ungiria con "aquel bendita sensación de tener la razón siempre" $(1951,211)$ que parecian sentir los comunistas. Así lo expresaba su personaje en Fellow Travellers, el libro que Worsley escribió sobre el viaje con Spender por la España de la guerra:

Afiliarse al Partido Comunista era algo diferente. Era el equivalente de cambiar de religión. Era un acto de fe. El Partido, como los católicos, exigía absoluta obediencia. Si te afiliabas, tenías que renunciar a la libertad de pensar por ti mismo. Pensabas lo que se te decía que pensaras (...) Era un acto de renuncia además de fe, y a cambio se te daba la certeza absoluta $(1971,145)$.

Isaiah Berlin, uno de los amigos oxonienses de Spender, desharia el espejismo por el que su generación se había dejado fascinar: el marxismo -o, puntualizo yo, el marxismo-leninismo- ${ }^{2}$ comportaba un historicismo profético, una lógica determinista, pero al mismo tiempo exigía el sacrificio, en una flagrante paradoja porque, si tan inexorable era el rumbo de los acontecimientos, ¿para qué forzarlos en una determinada dirección? $Y$, sobre todo, ¿cabe engañarse con el precio que es preciso pagar? Spender se definía en las primeras páginas de Forward como un liberal "dispuesto a trabajar por una sociedad comunista si se le convence de que así aumentará la libertad". Pues bien, la reflexión de Berlin suena casi como una tardía réplica a su amigo. "Un sacrificio -establecería en Dos conceptos de la libertad (Berlin 1998,63)- no entraña un aumento de lo que se sacrifica, por muy grande que sea su necesidad moral o por mucho que compense". No debe perderse de vista que el gran libro que ocupó a Berlin durante los años treinta, y que Spender leyó en 1939, era precisamente su biografía de Marx: en la revisión de sus ideas políticas tras la experiencia española sin duda jugó un papel crucial el pensamiento de su amigo, que lo obligaba a volver el rostro a los aspectos menos halagüeños de las actitudes políticas que había adoptado durante un tiempo. Claro está que al argumento de Berlin subyace un presupuesto liberal que hunde sus raíces en el humanismo ético y político moderno, de fundamento kantiano: el imperativo de que es preciso tratar siempre a los hombres como fines y no como medios, y el corolario de que no existe fin superior al individuo mismo. Pues bien, esta idea liberal, de la que Spender se había declarado en sedición, encontraba su contrapunto más extremo en la estética del sacrificio que propugnaba la ortodoxia política de la izquierda y que alcanzaba su apogeo en la apelación al heroísmo y la comprensión de la violencia como holocausto. Como escribiria Laurie Lee $(1991,46)$, la guerra de España ofrecía a aquellos jóvenes idealistas, ante todo, "la oportunidad de realizar un rotundo y enorme gesto de sacrificio personal".

\section{HÉROES Y MÁRTIRES}

Este sacrificio dejó muy pronto de ser una idea y adquirió un rostro, el de algunos voluntarios británicos más o menos ilustres cuya muerte convirtió la Guerra Civil española en un escenario épico. Entre los escritores, los más relevantes fueron Julian Bell, John Cornford, Charles Donnelly, Ralph Fox y Christopher Caudwell. El caso de algunos fue especialmente sonoro y dio origen a cierta leyenda: Cornford, el joven comunista y poeta de aliento romántico, recibiría el homenaje de Pat Sloan en John Cornford: A memoiry figuraria en los relatos Volunteer in Spain de John Sommerville y The Spanish Cockpit de Franz Borkenau, que combatieron a su lado en Madrid y Aragón respectivamente. En cuanto a Ralph Fox, fue precisamente John Lehmann, coeditor de Poems for Spain junto con Spender, quien editó el homenaje Ralph Fox: A Wrtiter in Arms. Sus tempranas muertes, ambas el 27 de diciembre de 1936, los erigieron en figura simbólica para el resto de la contienda. "En vuestros momentos de vacilación -exhortaba Randall Swingler en el primer verso de "They Live"- recordad a Cornford y a Fox". 
Y Sommerville declaraba en el último párrafo de su libro: "Para mí John es el arquetipo y el símbolo del joven de hoy, cuya tarea consciente es cambiar el mundo".

Spender no fue del todo ajeno a la gestación de leyendas de esta especie. De hecho, fue uno de los articulistas que se apresuraron a rendir homenaje a Fox al llegar a Inglaterra la noticia de su muerte, el 5 de enero de 1937. Pero conviene reparar en los sentimientos encontrados que a este respecto harán presa en él durante la guerra. Por ejemplo, en su poema "Fall of a City", ante la noticia de la caída de Barcelona en los periódicos, evoca la ciudad revolucionaria que conoció en sus estancias en España en un tono irremisiblemente elegíaco. Se trataba de una pérdida especialmente preciada para él, que en su primera visita con Tony a España, todavía antes de la guerra, no había disfrutado del viaje hasta que llegó a la capital catalana, que le sedujo con su aire cosmopolita, la ortogonalidad perfecta de su plan Cerdá, el encanto de sus edificios modernistas y las construcciones que la Exposición Universal había dejado tras de sí. Después, en su primer viaje a la España en guerra, Barcelona se había convertido ante sus ojos en el símbolo de la nueva situación: "La gente de esta ciudad sabe que es libre", había escrito en uno de sus artículos. Ahora, tras la derrota, todo parecía volatilizarse como un sueño: si Barcelona había sido la imagen misma de la revolución, lo que se le avecinaba era una súbita contrarrevolución. Los jóvenes tendrán que olvidar las lecciones aprendidas, los carteles y panfletos serán barridos por la lluvia y el viento, las insignias y los saludos se desvanecerán... ¿Qué hay de los héroes? Ubi sunt? 0, mejor dicho, Ubi erint?

\section{All the names of heroes in the hall \\ Where the feet thundered and the bronze throat roared, Fox and Lorca claimed as history on the walls, \\ Are now angrily deleted \\ Or to dust surrender their dust, \\ From golden praise excluded (Spender 1985, 47).}

Se trataba de una lógica previsible: los vencedores escribirian su propia historia, y en la desaparición de aquel efímero papel impreso de carteles y panfletos se cifraba la imposición de una lectura única de los acontecimientos, que el nuevo régimen sin duda acometería: expulsados del templo, excluidos de la "dorada alabanza", los nombres de los héroes derrotados permanecerían sólo como un recuerdo trágico que se contempla en silencio.
Spender sintió también en un primer momento la tentación de aquel heroísmo trágico consagrado por la literatura de la Gran Guerra: joven, bien parecido, alto y esbelto, de ojos claros y rubia y desordenada cabellera, casaba a la perfección con el arquetipo del efebo ofrecido en holocausto. De hecho, los modelos literarios de esta actitud -Byron y Brooke, que habían entregado su vida en Grecia $y$ en el frente occidental, respectivamente- no quedaban lejos de su biografía. En 1914 su tío había enviado a Brooke a los Estados Unidos a escribir unos artículos para la Westminster Gazette y de algún modo el malogrado poeta había formado parte de la memoria familiar. Además, en la revista New Verse se había calificado al propio Spender como "el Rupert Brooke de la Depresión", en un embarazoso sambenito para un joven más amigo del verso descarnado y ácido de un Owen que de la eufonía patriótica y tópica de Brooke. En cuanto a Byron, suponía una presencia aún más poderosa: por ejemplo, Koestler relacionaba el fantasma de Byron con las motivaciones de muchos de los brigadistas que se alistaban con entusiasmo en 1936 y John LangdonDavies describía con sonrojo la afición de los intelectuales españoles a contemplar a todo poeta inglés que apoyara la causa republicana como "el Byron de nuestros días", mientras Harry Pollitt, en A Writer in Arms, se refería a Fox como "un Byron moderno". Por otra parte, como resulta natural, Spender había tenido a Byron entre sus primeras lecturas, a principios de los años veinte. Así, no debe extrañar que, cuando Pollitt lo envió a Valencia con el comentario de que debía "hacerse matar, pues necesitamos un nuevo Byron para la causa", aquella perspectiva heroica le provocase un vértigo momentáneo. Presa de la ingenuidad, aquel día Spender visitó a los Woolf, con los que tenía trato frecuente desde que su amigo John Lehmann trabajaba en la Hogarth Press. En una entrada del 16 de febrero de 1937, el diario de Virginia Woolf deja una elocuente constancia del estado de ánimo del joven poeta en aquel momento inicial:

Stephen Spender vino a tomar el té y a cenar el otro día [...] Un joven de gran entusiasmo, ahora atemperado porque, al casarse él, su amigo se ha alistado en la Legión Extranjera (sic) y combate en España [...] Dijo que el Partido Comunista, al que se había afiliado ese dia, quería que lo matasen en España para que hubiese un nuevo Byron. Tiene una pueril vanidad sobre su propia persona (Woolf 1985, 56).

El disgusto de los Woolf y del grupo de Bloomsbury en general era más o menos previsible dado su recelo ante 
todo lo que supusiese una actitud de compromiso político. En la encuesta Authors Take Sides, Virginia Woolf se negó a responder, mientras Vita Sackville-West afirmó estar "harta" de que se solicitasen de ella manifestaciones de este tipo. Tanto una como otra contaban con varias razones, además de la estrictamente literaria o estética. En lo que respecta a Virginia, su sobrino favorito, Julian Bell, hijo de su hermana Vanessa y del crítico de arte Clive Bell, había evolucionado desde sus iniciales actitudes pacifistas hacia el socialismo y se había alistado, lo que le condujo a la muerte en Brunete en julio de 1937. En su figura, cuya pérdida sumió a la novelista en una profunda pesadumbre, los Woolf contemplaban el entusiasmo romántico y desbocado, preñado de expectativas desmesuradas, de una juventud que desconocía la realidad de la guerra. Por otra parte, Spender parecía especialmente susceptible de caer presa de ese romanticismo: el punto de partida del libro que acababa de escribir, Forward from Liberalism, era precisamente la idea de que el romanticismo había sido un proyecto truncado y que, en consecuencia, el izquierdista del momento buscaba simplemente "realizar lo que el romántico había dejado sin hacer". Cuando en aquellas páginas exigía "justicia política", Spender se estaba remitiendo literalmente a una fuente mucho más concreta de lo que pudiera parecer: Political Justice (1793) ${ }^{3}$, el legendario ensayo de William Godwin, padre de la segunda esposa de Shelley y autora de Frankenstein.

En lo que se refiere a Vita Sackville-West y su marido el diplomático Harold Nicolson, puede decirse que contaban con razones menos cruentas para desalentar al joven Spender. Ambos habían invitado a cenar con ellos en su castillo de Sissinghurst, el 9 de agosto de 1937, a un Auden y un Spender casi recién regresados de su experiencia española. ¿Qué escribió Nicolson en su diario de aquella velada? "Stephen Spender está más Shelley que nunca", tal vez en alusión al argumento de Forward, donde Spender hacía pie repetidamente en el poeta de Adonais. En fin, decir Shelley o decir Byron era aquí prácticamente lo mismo: en el contacto con los Nicolson, a quienes también frecuentaba Spender a finales de la década, el joven poeta podía encontrar una nueva ocasión para abandonar aquel culto al héroe romántico, porque Harold Nicolson era autor de una revisionista biografía de Byron, El último viaje (1924), que deshacía muchos de los mitos victorianos sobre la figura y trataba los últimos episodios de su vida con distancia e ironía. Si Spender necesitaba un antídoto para la biografía heroica de André Maurois Lord Byron (1930), que habia leído a comienzos de la década y había discutido con sus amigos alemanes, lo tenía al alcance de la mano. Así, pocos días después de su primera visita, Spender volvió a visitar a los Woolf y Virginia escribió en su diario que Spender "se tomaba ahora a broma lo de hacer el Byron".

¿Hasta qué punto cabía el humor en aquella pose? En World within a World Spender desveló las dudas entre las que se había debatido en aquel otoño de 1936, mientras tantos escritores jóvenes se alistaban en las Brigadas Internacionales. Se trataba de un conflicto "entre su conciencia artística y su conciencia pública, y era imposible fundir ambas en una sola". Había llegado el momento de elegir entre el fusil y la pluma: la primera era la opción de los que se alistaron y "suyo era el papel de mártires", declaraba; la segunda, en cambio, era la posición del cronista, atento a una perspectiva más distante y completa de los acontecimientos. Para comprobar la imagen que proporcionaba esta perspectiva basta citar un párrafo de su artículo titulado precisamente "Heroes in Spain", en el que relata la historia de "Harry", que había acudido inicialmente como corresponsal de "uno de los periódicos británicos más reaccionarios", luego se había alistado en las Brigadas Internacionales y, tras contemplar la muerte de uno de sus compañeros en los olivares de Albacete, había perdido la razón.

Cuento esta historia como contrapunto a la propaganda sobre los héroes en las guerras. El horror definitivo de la guerra es la completa soledad de un hombre que muere solo en un mundo cuya realidad es la violencia. Los muertos en la guerra no son héroes: son puñados helados o podridos de una locura solitaria. La gente intenta evitar caer en la cuenta de la violencia a la que las ideas abstractas y los altos ideales les ha conducido arguyendo o bien que los individuos no importan o que posmuertos son héroes. Puede que sea cierto que a veces las vidas de los individuos no importen en relación con el conjunto de la historia futura, pero decir que los que resultan muertos son héroes supone un intento perverso de identificar a los muertos con las ideas abstractas que los han traído al frente y añadir así prestigio a esas ideas, que se emplean para empujar a los vivos a muertes igualmente "heroicas" (Spender 1978, 49).

No extraña que esta lucidez desagradase a los nuevos correligionarios de Spender. Al toparse con la realidad concreta del frente, el autor de Forward from Liberalism se 
estaba desdiciendo de aquella tesis fundamental sobre el sacrificio del individuo en el altar del futuro colectivo. Esta primacía de lo concreto contra los ideales abstractos era además una de las afirmaciones éticas más clamorosas de la literatura de la Gran Guerra: hastiados de contrastar la jerga oficial de la propaganda, las arengas patrióticas y las apelaciones al heroísmo con la realidad física del frente, los soldados, como escribía Heminway en Farewell to Arms, sentían que "había muchas palabras que no se podían tolerar y, a fin de cuentas, sólo los nombres de las localidades habían conservado cierta dignidad [...] Las palabras abstractas como gloria, honor, valentía o santidad eran indecentes, comparadas con los nombres concretos de los pueblos" $(1964,175)$. Curiosamente, el escritor con el que más cafés y conversaciones compartió Spender durante su visita a Albacete y al frente de Madrid no era otro que el viejo Hem.

La propaganda que Hemingway y otros habian descalificado con ocasión de la Gran Guerra insistía ahora en un discurso que ofrecía la muerte como victoria: un regreso al ritual romántico. Spender contaba con la ayuda de Isaiah Berlin para advertir este oxímoron de la lógica sacrificial, pues al estudiar precisamente la figura de Byron, observó Berlin que en realidad su heroísmo era de estirpe prometeica: más que la negación de sí, a su gesto subyacía la autoafirmación del dandy. Es más, cuando analiza las ideas políticas asociadas al romanticismo, Berlin describe este movimiento como uno de los antagonistas de la Ilustración, puesto que en él "los valores no se descubren sino que se inventan", lo que explica la "admiración romántica por el mártir y el héroe" (Berlin $2006,2)$. Ahora bien, al denunciar la excesiva "devoción" fichteana por la visión de cada cual y "el nihilismo byroniano" de esta actitud, Berlin señala hacia un camino que nos devuelve a los modelos literarios de la Gran Guerra. Durante las últimas décadas victorianas y los años de la "Paz armada", e incluso durante la contienda, había predominado esta imagen romántica formulada por Carlyle en su ensayo Los héroes. "Héroe -definía Carlyle $(1985,174)$ - es aquel que vive en la esfera íntima de las cosas, en lo verdadero, en lo divino, en lo eterno, en lo invisible a los más". No en vano algunos de los personajes que proponía en su ensayo eran Lutero, Calvino, Knox... Un énfasis fichteano en la interioridad como fuente de verdad y autenticidad.

La guerra permitió una ácida revisión de esta figura estetizante del héroe en manos de un objetor de conciencia: Lytton Strachey. De hecho, puede decirse que lo que Stra- chey hizo en Eminent Victorians, publicado precisamente en 1918, fue toda una provocación: tomó la figura del gran héroe victoriano, el general Gordon, y la sometió a un proceso de irónica desmitificación. Al permanecer en Jartum, pese a las órdenes del Gobierno de retirarse, Gordon simplemente habría intentado satisfacer su avidez de gloria, la descabellada idea de sí mismo de un visionario aficionado a leer la Biblia y el Gerontius de Newman. Se trataba, por tanto, de una muerte buscada: en ella había la promesa de una gloria definitiva.

Pues bien, las circunstancias de 1936 parecian haber borrado la lección antiheroica de un Strachey o un Owen. El nuevo culto al héroe que promovía la propaganda, obra fundamentalmente del Partido Comunista, suponía entre otras cosas una maniobra de ocultación de lo que acontecía en aquellos momentos en la URSS. Lo curioso del caso es que Spender no se había engañado en ningún momento acerca de la imposición estalinista y la purga de los trotskistas. Es cierto que sus amigos Rex Warner, Cecil Day Lewis y Randall Swingler habian publicado en la Left Review poemas en los que cantaban las bondades de la URSS, y que él mismo había citado en Forward from Liberalism el libro de Beatrice Webb, Soviet Communism, A New Civilisation?, que se había convertido en uno de las revelaciones de la década. En los últimos capítulos, Spender habia llegado incluso a justificar "el asesinato necesario", como lo expresaría Auden en su poema Spain. "Aunque un Frente Popular francés o inglés son posibles sin excesos -advertía alli $(1937,294)$ - debemos apoyar al Frente Popular español sin cegarnos al hecho de que en España los excesos son inevitables", una frase que servía tanto para el asesinato de los franquistas como para la eliminación de los republicanos disidentes. No obstante, Spender advertía al mismo tiempo del peligro de convertir la ortodoxia política en un fin en sí y criticaba los juicios a Zinoviev, Kameneff y otros trotskistas, "prejuzgados por la prensa gubernamental". Además, en su entrevista con Pollitt había dejado claro que era una cuestión que le suponía un obstáculo para afiliarse al Partido. Sin embargo, de algún modo había decidido posponer la elucidación final del problema, siguiendo la lógica del sacrificio de la crítica, puesto que en aquel momento él y Pollitt estaban en perfecto acuerdo sobre la Guerra de España: de una manera menos cruenta que los "mártires" Cornford, Fox, etcétera, había consentido en que el Partido lo utilizase circunstancialmente. 
De este modo, sería fácil describir el itinerario de Spender como un tránsito de la ingenuidad a la plena advertencia, pero lo cierto es que más bien puede caracterizarse como un viaje desde la abstracción y el cinismo hacia la conciencia ética concreta. Cuando llegó el momento de contemplar el rostro que adquiria aquel conflicto de ideas, no pudo sino quedar horrorizado: por ejemplo, durante el Congreso de Intelectuales Antifascistas escuchó cómo el conductor catalán de su coche alardeaba de haber asesinado a sangre fría a seis personas, en la liquidación del POUM en Barcelona, que había desembocado en los combates callejeros de mayo de 1937, mientras los demás pasajeros, los comunistas Frank Pitcairn, Ralph Bates, Sylvia Townsend Warner y Edgell Rickword, permanecian impertérritos. Si a esto se le añade la amenaza que recibió de Pollitt a su regreso a Londres de que, en caso de que criticase públicamente al Partido, se le chantajearía como "intelectual homosexual", no extraña que el joven poeta abandonara pronto su militancia comunista. Así, puede decirse que fue precisamente su relación con el Partido, y la actitud del Partido ante la guerra, lo que desencadenó su decepción: antes de publicar Forward from Liberalism había escrito a Herbert Read confesándole que en su fuero interno era comunista "desde hacía un año". El problema, claro, era que al expresarse en el mundo objetivo, fuera de la idealidad y la abstracción pura de su intimidad, aquel comunismo había adquirido un aspecto menos halagüeño. La guerra reeditaba el viejo conflicto entre experiencia e idea, hasta mostrar que "por muy sinceros que sean los escritores marxistas, es inevitable la dominación de sus mentes por una teoria anterior a la experiencia" (Crossman 1951, 336). Y un lector de Owen, como era Spender, no podía vacilar en abrazar la verdad de la experiencia.

Contra el discurso de la abstracción que propugnaba la propaganda, Spender terminaría por abrazar una suerte de "doctrina de la caridad universal", fruto de su "idiosincrasia apacible" y del "lado cristiano de su naturaleza", como observa Pujals $(1985,12)$. No en vano el origen de sus ideas sobre la justicia social, según recuerda el propio Spender en The God that Failed, estaba en el Evangelio, y una de las mayores dificultades que había superado para abrazar el comunismo era además la instintiva "piedad" que sentía hacia las víctimas de una revolución. Así, lo que delata su actitud tras la Segunda Guerra Mundial, cuando argumenta que no se tenía por políticamente reaccionario "por creer en Dios o por tener ideas acerca de la naturaleza o de la Humanidad que no fuesen exactamente 'científicas' en el sentido marxista", es un cierto conato de trascendencia que tiene mucho que ver con el abandono de lo que el marxismo tiene de historicista y de materialista. De este modo, no extraña que, tras el desengaño político, el discurso de World within a World examine las propuestas religiosas con las que Spender contaba a su alrededor: el anglicanismo ortodoxo de Eliot, el más heterodoxo de Auden y la inquietud por el hinduismo filosófico de Isherwood. Si deseaba servir a alguna causa, la mejor por la que podía decantarse el escritor era la del hombre mismo, y la imagen del hombre que empezaba a anidar en el interior de Spender era ajena a la de un elemento inmerso en una totalidad indiferenciada, presa de las estructuras socioeconómicas:

Para mí las creencias de los poetas son revelaciones sagradas de una realidad acerca de la naturaleza de la vida que no puedo compartir, pero que no puedo ni deseo explicar como un "fenómeno social". Si el arte nos enseña algo es que el hombre no está completamente aprisionado dentro de su Sociedad (Crossman 1951, 338).

$\mathrm{Ni}$ que decir tiene que, desde la óptica marxista, este tipo de consideraciones devolvian a Spender a un discurso romántico, amigo de las entelequias carentes de relevancia histórica, que tal vez no había abandonado nunca en realidad. En cambio, desde la óptica de Spender quienes incurrian en ese lenguaje fantasmal eran los marxistas 0 , más bien, los estalinistas que convertían las vidas de los disidentes en "abstracciones" de las que no costaba mucho prescindir. En su opción por la idea y contra la experiencia, los que permanecían fieles a la ortodoxia política de la izquierda quedaban obligados a cerrar los ojos ante un número de bajas que a Spender sencillamente le resultó excesivo. El amor a la Humanidad, con la que los miembros de la delegación británica se llenaban la boca en el Congreso de Valencia, debía empezar por la piedad con los hombres concretos que uno encontraba a su alrededor.

\section{El CENTRO fiJO}

El desencanto ideológico y el regreso al individuo concreto como referente primero y protagonista de la Historia die- 
ron como resultado un retorno de Spender al que siempre había sido su propio cauce. Si la adhesión a la causa comunista comportaba la disolución del individuo en el plasma de la masa colectiva, su abandono invitaba a una literatura del yo que cabía tomar como correlato retórico de la ideología liberal. Por grande que sea "el desprecio de los sentimientos personales" debido a las exigencias políticas, escribiria en World within a World, "uno no puede escapar del hecho de que cuenta con un yo interior" (1951, 254). Así, el paso del "yo" al "nosotros" en el que los jóvenes escritores aspiraban a purgar su origen burgués - por ejemplo, el Anthony Neale de Starting Point, la novela iniciática de Day Lewis cuyo protagonista se incorporaba a la lucha obrera- terminaba por revelarse impracticable. Por muchas consignas que se repitiesen, aquellos hijos de Oxford conservaban un individualista instintivo y, más que un "nosotros", lo que quedaba más allá del yo era el "ellos". La vida de las masas, uno de los temas de la literatura de la década -entre otras razones, debido a la difusión del ensayo de Ortega, traducido al inglés en 1932- dejaba de ser el centro de atención, y en especial para un Spender que ya en sus años de Alemania había comprobado los peligros que comportaba una multitud enfervorizada en manos de un orador hábil y vehemente.

Curiosamente, el descubrimiento de esa vida interior del individuo como realidad radical e irrenunciable no era en Spender ajeno al drama de la guerra. En el poema "A First War Childhood" recordaría cómo, una noche de marzo de 1916, despierto sobre la cama en la casa familiar de Norfolk, imaginaba los submarinos acercándose a la costa y los zeppelines intratando bombardear Londres, cuando de pronto del cielo vacío "cayó una voz / como una cascada / diciendo a través del espacio: / YO SOY, YO SOY, YO SOY. / Luego explotó una bomba" (Spender 1994, 35). Se trata de una obvia referencia yahvista, pero filtrada a través de la idea de Coleridge de que el yo supone "el eco en la mente finita del infinito 'Yo soy'": una suerte de epifanía secularizada, porque lo que se revela en la incertidumbre, en el miedo del niño ante la noche, es más bien la conciencia que la Persona de un Dios. Como si la amenaza de la muerte mostrara con mayor intensidad el hecho de la vida del individuo, reclamase su atención, lo primero que haría el niño tras el estruendo de las bombas sería palparse a sí mismo, cerciorarse de seguir vivo, cobrar esa conciencia. Pues bien, uno de los poemas españoles de Spender, "Thoughts During an Air Raid", recupera ese escenario bélico para volver sobre el tema de la conciencia individual:

Of course the entire effort is to put oneself

Outside the ordinary range

Of what are called statistics. A hundred are killed

In the outer suburbs. Well, well, one carries on.

So long as this thing ' $I$ ' is propped up on

The girdered bed which seems so like a hearse,

In the hotel bedroom with the wallpaper

Blowing smoke wreaths of roses, one can ignore

The pressure of those names under the fingers

Indented by lead type on newsprint,

In the bar, the marginal wailing wireless.

Yet, supposing that a bomb should dive

Its nose right through this bed, with one upon it?

The thought's obscene. Still, there are many

For whom one's loss would demonstrate

The 'impersonal' use indeed. The essential is

That every one should remain separate

Propped up under roses, and no one suffer

For his neighbour. Then horror is postponed

Piecemeal for each, until it settles on him

That wreath of incommunicabe grief

Which is all mystery or nothing (Spender 1985, 74) ${ }^{4}$.

En "Spain Invites the World's Writers" Spender referia uno de esos bombardeos en los que posiblemente se inspira el poema: el que tuvo lugar en el hotel Victoria de Madrid, durante el Congreso de Intelectuales Antifascistas, en una velada que Alberti interrumpió bruscamente para alertar a los escritores sobre la llegada de las bombas. Creo que se trata de uno de los poemas más reveladores entre los que Spender escribió sobre su experiencia en España, pese a lo aparentemente elusivo, alambicado o especulativo de su discurso. Lo que en él encontramos es ese redescubrimiento del individuo como realidad radical, que el bombardeo resucita contra la trivialización de las cosas que supone la estadística, esto es, la desaparición de la persona como tal en la aritmética de la muerte y su anonimato postrero, en el estilo "impersonal" con el que la gramática enmascara la verdad cruda de la guerra. Bernard Spencer había mostrado la impasibilidad del lector ante la fría elocuencia de las cifras, en el conocido poema "I Read of a Thousand Killed", donde el narrador se alegra de esas muertes si han servido para "morder la garra" del imperio opresor. Contra ese tratamiento desde el punto de vista del todos, el poeta 
que soporta el bombardeo presa de su propio miedo, en la habitación del hotel, esperando que en cualquier momento asome la nariz una de esas bombas, redescubre el valor del cada uno, en lo que Koestler formularía como una inversión de la máxima ética de Bentham: de lo que se trataba ahora era de lograr "el menor sufrimiento para el número menor de gente".

De hecho, "Thoughts" casi sugiere que a cada uno toca su parte en el sufrimiento común, como una suerte de cuota que un fatum impasible les adjudica: al caer desde el cielo, las bombas de los aviones escenificaban un dies irae que el tono apocalíptico de la poesía de los treinta casi había previsto. Poemas como "Bomber", de Jacob Bronowski, "Bombing Casualties", de Herbert Read, "Bombers" de Cecil Day Lewis, "The Bombers" de Grigson y "Elegy on Spain" de George Barker tratan también el tema del bombardeo aéreo. "Mi propia fantasía privada - confesaba Spender a propósito del Blitz que comenzaría poco después en Londres- era que salía de un sótano tras el primer ataque aéreo sobre Londres y encontraba un paisaje compuesto únicamente de ruinas" $(1978,11)$. Ante la catástrofe definitiva, sólo parecía quedar en pie la certeza de la conciencia individual. Y la cultura del sacrificio podía llevar a la civilización no a la salvación final que sus correligionarios habian cantado sino a la destrucción completa, de la que la guerra de España suponía una advertencia bastante elocuente como para obligar al poeta a replantearse algunas cuestiones. Como escribiría en September Journal, lo que en Valencia, en Barcelona y en Madrid había contemplado durante los bombardeos nocturnos era "la mirada de adiós de la luna a nuestra civilización". Su conclusión queda expresada mejor que en ninguna otra parte en "Heroes in Spain", donde desvela aquella lógica sacrificial y su transformación de la realidad concreta en una abstracción, para reclamar el regreso a la realidad inalienable del individuo:

La gente intenta evitar darse cuenta de la violencia a la que las ideas abstractas y los elevados ideales les ha llevado a base de decirse o bien que los individuos no importan 0 bien que los muertos son héroes. Puede que sea cierto que en ocasiones las vidas de los individuos no importen en referencia al conjunto de la Historia futura, aunque la muerte violenta de muchos individuos puede modificar la conciencia de toda una generación tanto como una obra de arte o un tratado de filosofía. Pero decir que los que mueren son héroes supone un malvado intento de identificarlos con las ideas abstractas que los han llevado al frente, añadiendo asi prestigio a esas ideas, que se emplean para llevar a los vivos a otras muertes "heroicas" (Spender 1978, 49).

De este modo, los años posteriores a sus estancias en España empujaban furiosamente a Spender hacia el discurso de la palinodia: su itinerario podía describirse cómicamente como Backwards to Liberalism, en un gesto que muchos interpretaban como la autojustificación del renegado pero que cabe leer sencillamente como un acto de sinceridad consigo mismo. ¿Que el burgués vive, como él mismo había denunciado en Forward, inmoralmente "centrado en el yo", en "su pequeño universo individualista"? Ciertamente, pero saberlo no iba a facilitar las cosas: toda negación del yo acontecía siempre desde el yo mismo, que quedaba afirmado en otra instancia, y de ahí que el sacrificio al que su generación se mostraba tan aficionada ocultase en muchos casos la lógica del narcisismo. Je est un autre. No cabía ya engañarse sobre la bondad de las masas, ni siquiera sobre la posibilidad de sumarse a ellas: la condición natural del hombre era la insularidad, aquel paisaje de "islas en tus mares privados / donde los pensamientos descansan como náufragos", sobre el que Auden había ironizado en "A Communist to Others". Y Spender sabía algo sobre islas. La mayoría de los artistas se ven forzados a ser "individualistas que no expresan sino su propio aislamiento", había escrito en 1933. "Nacer", escribiría casi veinte años después, "es convertirse en un Robinson Crusoe". Lo que quedaba entre ambas declaraciones era sólo un paréntesis.

En su caso, junto con su clase social, pesaba una cierta tradición literaria que lo empujaba en una dirección centripeta, hacia el espacio interior de esa conciencia ética redescubierta en España. Por un lado, como ya he comentado, había leído a Freud ya en sus días de escolar, gracias a Auden tenía noticia de las ideas de Rivers, Layard y Lane y Virginia Woolf le había presentado a su cuñada, la psicoanalista Karin Stephen, con la que el poeta comenzó a hacer terapia. Por otro, y pese a los consejos de su amigo Auden, era dentro de su generación la voz más cercana a un tono romántico, solitario y enormemente autoconsciente. Ambos factores, psicoanálisis y romanticismo, le inducían a regresar a aquella "torre de marfil" que la encuesta de Nancy Cunard había declarado abolida. Si a esto se le añade la crisis matrimonial y el doloroso divorcio por el que había pasado -Inez lo había dejado por el poeta y sociólogo 
Charles Madge en el verano de 1939- no extraña que el poeta volcase su atención sobre sus problemas personales y su propia intimidad". En los últimos versos de "The Double Shame", uno de los poemas sobre su separación de Inez, se fustigaba a sí mismo escribiendo que "al principio no amaste lo suficiente / y luego amaste demasiado", como si haber pasado aquellos años ejerciendo el papel de escritor comprometido le hubiese llevado a descuidar su vida conyugal. En World within a World explicaba que, pese a haber existido entre Inez y él un amor verdadero, "no era del tipo que pudiera hacer que sintiéramos que éramos una sola persona". Y en September Journal relacionaba su estado de ánimo con dos cataclismos de distinta índole y escala: el estallido de la guerra y su ruptura matrimonial.

Para un poeta que había contemplado de cerca los acontecimientos de la década -la caída de la República de Weimar, el ascenso del nazismo, el Anschluss austriaco, la guerra de España- iniciar en septiembre de 1939 un diario parecía entrañar toda una declaración de intenciones: mientras el mundo se hundía en el colapso público, él regresaba al redil de sus mundos privados, en una lógica del contrapunto que se obtenía del desencanto político. Si Forward from Liberalism había supuesto, como él mismo reconocía, un torpe discurso apegado al análisis histórico y ajeno a "la experiencia personal", sus vivencias en España le habian recordado su mayor idoneidad para una literatura escrita desde el yo. Era un resultado casi previsible: al consignar una visita de Spender en su diario de finales de 1937, Virginia Woolf observaba con perspicacia que el poeta "habla menos de política y vuelve a una extrema preocupación por los problemas del yo". Y, de hecho, el contacto con los Woolf fue más determinante de lo que pudiera parecer. En una entrada del 20 de octubre de su September Journal, Spender recordaba así una visita a la casa de los Woolf en Rodmell, cerca de Lewes:

Después del té [...] Virginia y yo paseamos por el jardín hablando de la escritura, que dijo que era un tema que quería tratar con otros escritores. Le alegraba que yo llevara un diario porque decía que a su juicio era también lo único que ella podía hacer. Pensaba que todos los días surge alguna ocasión en que uno ve las cosas de un modo completamente nuevo y diferente, y que esos momentos de transformación son nuestra percepción de la realidad. Esa es la experiencia que ella intenta captar en su diario (Spender 1985, 49).
Y, por extensión, cabe decir que ésa es también la experiencia que Spender empezaba a buscar con sus propios diarios: ante el desconcierto y la incertidumbre del orden de las naciones, el escritor se ejercitaba en una acendrada percepción personal, como intentando cerciorarse de que su existencia qua individuo seguía su curso. Esta coincidencia con Woolf es sumamente reveladora: pese a sus veleidades comunistas y a sus intentos de acordar el paso con los imperativos estéticos que comportaba la ortodoxia política, Spender estaba "naturalmente" inclinado hacia esa literatura egocéntrica no sólo por su clase social y su educación oxoniense, sino por el mundo literario en el que se había zambullido al abandonar la Universidad. ¿Quiénes habían sido alli sus nuevos "tutores"? Eliot, que lo había tomado como protegido, había publicado sus poemas en Faber \& Faber y conservaría con él una amistad vitalicia; Woolf, que lo había adoptado casi como un sobrino más; Herbert Read, con quien mantenía una intensa correspondencia; Vita Sackville-West y Harold Nicolson, quienes lo habian orientado también en algunos momentos; y $E$. M. Forster, tan crucial en la educación sentimental de su generación. En suma, un breve repaso a las amistades literarias de Spender entre la generación de sus mayores arroja un saldo inequívoco: los nombres que más podian influir en su pluma eran los modernistas del círculo de Bloomsbury y sus aledaños, de cuya lista sólo faltaba un Joyce perdido en el Continente. No extraña, así, que David Leeming $(1999,7)$ haya resumido su figura como la de "un poeta en la línea modernista, pero confesional", a quien sólo la intensísima preocupación política de la época habría desviado momentáneamente de su senda.

Lo más interesante de este juicio de Leeming es el pero: en la lectura habitual del modernism la crítica entreveía la expresión de una crisis en la que la visión unitaria del mundo y el yo mismo habrían estallado en pedazos. Todo lo que quedaba, como rezaba el conocido verso de The Waste Land, era a heap of broken images: la idea romántica de un universo animado por el yo del poeta, que proyectaría sobre él las formas de su imaginación, quedaba obsoleta, incapaz de expresar la situación moderna. De hecho, algunos de los nombres más destacados del modernism, como Eliot, eran militantes en su antirromanticismo. Como es obvio, esta interpretación ponía el acento en la discontinuidad histórica, en la medida en que entendía que esa situación moderna proporcionaba al individuo un tipo de experiencias insólito, rigurosamente novedoso, imprevisto 
en cualquier programa literario anterior a 1910, cuando, como escribía Woolf, "la naturaleza humana cambió".

Ahora bien, precisamente en el momento en que Spender regresaba a su escritura confesional esta interpretación del modernism conocía una brillante revisión: en Axel's Castle (1936), Edmund Wilson sostenía la tesis de que, del mismo modo que Valéry y Proust eran en Francia un desarrollo ulterior del simbolismo decimonónico, Eliot y Joyce $-y$, con ellos, todo el modernismo- se podían comprender como un producto tardío o una "extensión" de un simbolismo que nunca había arraigado del todo en suelo inglés. ¿En qué medida? En la medida en que a la escritura modernista subyace un yo simbolista 0 , si se quiere, romántico en último término: la stream of consciousness de Joyce, el monólogo interior de Woolf y el imagism de Eliot y Pound serían métodos diversos para mostrar "el impacto de los acontecimientos exteriores en la sensibilidad interior proyectada sobre la conciencia", como expresaría el propio Spender en The Struggle of the Modern $(1963,115)^{6}$. Es decir, que en último término subsistiria un yo de filiación romántica: más que un comienzo ex novo, el modernismo se edificaba sobre las ruinas del romanticismo o simbolismo de un yo cuya unidad y centralidad se distorsionaban, se fragmentaban o se alternaban en colisión con otros yos, pero se presuponían inevitablemente.

Sin duda la tesis de Wilson es a su vez susceptible de revisión, pero lo decisivo aquí es que a Spender, que en The Creative Element cita Axel's Castle como una autoridad, debió de parecerle bastante plausible: si se leen con atención algunos de sus ensayos, no es difícil encontrar muestras de que esa tesis había calado en su (interesada) comprensión del modernismo. En particular, hay un rasgo que se deriva de esta interpretación del modernismo y que Spender no podía dejar de advertir: los modernos eran agudamente conscientes de la situación contemporánea, pero no compartían sus valores y en muchos casos -sobre todo, Virginia Woolf- su técnica terminaba derivando en una estrategia para proyectar su propia sensibilidad sobre los personajes y alejarse de todo contacto con el mundo social. El viaje no era hacia fuera sino hacia dentro, hacia la intimidad del yo, puesto que por un lado "el método realista de describir los personajes como resultado de su medio social ya no podía recrear las verdades esenciales de la vida individual" (Spender 1963, 120) y, por otro, los personajes de esas novelas a veces eran "máscaras para la sensibilidad del autor" $(1963,129)$. En una palabra: escritores como Henry James habian dejado obsoleta la novela decimonónica: el espejo "a lo largo del camino" giraba ciento ochenta grados e intentaba reflejar la vida interior, en un flagrante regreso a la subjetividad como punto de partida. Pero ¿qué había al fondo de esa vida interior sino un yo de filiación romántica? En su ensayo "Short History of Pers. Pron. Ist Sing Nom.", Spender era rotundo: en el uso del yo "son los románticos los más cercanos a los modernos".

$\mathrm{Ni}$ que decir tiene que, entendido así, el modernism se ofrecía a Spender como una afirmación de los derechos de la conciencia individual, contra la creciente asfixia del izquierdismo engagé. El marxismo ortodoxo sostenía que no es la conciencia del hombre lo que determina su condición sino su condición lo que determina su conciencia, en la elevación de la coyuntura económica y social a causa primera que comporta el materialismo histórico. De hecho, el propio Marx había criticado la "mistificación" de Hegel, que tomaba un atributo del sujeto -la subjetividad-, lo emancipaba y lo transformaba en el sujeto mismo, concediéndole una existencia hipostática, cuando en realidad lo único que existe es el individuo real y no un ser espiritual que exista por sí mismo, autónomo respecto del mundo material. Al reivindicar un cierto espacio para esta autonomía, aun sin elevarla a un absoluto, los escritores de Bloomsbury recogían de algún modo la herencia del viejo idealismo y recordaban a Marx que, aun siendo indudable la realidad radical del individuo, la vida interior de ese individuo no puede reducirse a un producto social y que, al efectuar esa reducción, el propio Marx estaba haciendo abstracción de lo real mismo, a un precio que Spender había llegado a conocer bien en España.

Esta interpretación del modernismo tenía para el joven poeta una virtud sobresaliente: semejante intimismo, volcado sobre la vida individual, suponía una alternativa a los modos de los treinta, con su dogmática insistencia en lo social. "Un cuadro, un drama, una novela, incluso un poema, eran antes que nada un hecho social", explicaba Julian Symons $(1960,65)$ a propósito del Zeitgeist de la década. De hecho, la imagen de Bloomsbury y de los modernistas que Spender esboza en World within a World contiene ideas muy significativas: no sólo coincide con Wilson en subrayar el aprecio de algunos, como Eliot, por los simbolistas franceses, sino que describe la atmósfera del grupo 
como una "aristocracia" formada por "individualistas", que gustaba de departir con el economista Keynes o el diplomático Nicolson las cuestiones más trascendentales sobre la civilización europea. En suma, se les podía caracterizar como "artistas" consumados, que para producir su arte necesitaban un cierto grado de refinamiento y buen gusto a su alrededor. La animadversión hacia ellos que en muchos casos se palpaba entre los miembros de su generación se debía, a juicio de Spender, a un prejuicio político, dogmático y desmesurado, como el que Ilevaría a Garaudy (1966, 81) a afirmar que el subjetivismo supone "la ideología de una clase cuyo papel histórico positivo tocó a su fin hace tiempo", es decir, la burguesía:

Sin duda no eran malvados explotadores de los hombres y esperaban una recompensa mucho menor que la que hoy espera el escritor oficial soviético. Al mismo tiempo, su renta de "quinientas libras al año y una habitación propia" (la fórmula de Virginia Woolf en un conocido ensayo) decididamente los hacia remisos a sacrificar su independencia a la causa de la lucha de la clase obrera. Tenían conciencia de clase, conciencia incluso de un mar que los separaba de uno de sus contemporáneos con más talento: D. H. Lawrence, el hijo del minero. Pese a sus simpatías izquierdistas, la atmósfera de Bloomsbury era no obstante esnob (Spender 1951, 141).

No extraña que en estas palabras de Spender, lejana ya su época de compromiso con la izquierda, resonara un cierto eco apologético: lo que el poeta veía en sus mayores a su regreso de España era en gran medida un modelo aún vigente, tras el desencanto político, y este modelo se caracterizaba entre otras cosas por su resuelto apego a la independencia individual y al yo como centro de la escritura. La cercanía al mundo de Bloomsbury, después de aquellas peregrinaciones por una España de discursos, trincheras y puños en alto, significaba entre otras cosas la posibilidad del punto de vista autobiográfico, esa escritura privilegiada en la que, como explicaría Spender en "Confessions and Autobiography", uno "es visto por sí mismo y no por otros", lo que sirve para desvelar lo más interesante y profundo del ser, lo inasequible al ojo exterior que registra los acontecimientos públicos. "Si existe ese punto de vista desde el que contemplo el mundo, la verdadera historia del mundo no sería una suma de biografías sino de autobiografías" (1980, 119), propondría, recogiendo en cierto modo la conocida frase de Dilthey. Contra las pre- tensiones científicas del marxismo, se trataba de recuperar los derechos de la subjetividad, de ese centro de percepción inasimilable a ningún otro discurso. No es casual, por tanto, que el libro que recogía en 1939 sus poemas españoles y el relato de su crisis Ilevase por título The Still Centre ${ }^{7}$. Si bien muchos críticos lo celebraron como su llegada a la madurez, para los comunistas se trató de la voz de un renegado que siempre había dado muestras de tibieza: en su reseña para el Daily Worker, Alick Best escribió que el "centro fijo" del título era "un secreto retiro donde Spender observa el conflicto del propio Spender, que no está interesado en resolverlo sino en tenerlo, pues así puede sentir que su tarea es permanecer al margen y contemplarlo" (ver David 1992, 215) ${ }^{8}$

Esta luxación, este ejercicio de contorsionismo de un yo introspectivo, es patente en uno de los poemas más importantes del libro, "Darkness and Light". Durante años, la posición ideológica de Spender, su origen social, sus amistades, su condición parcialmente judía e incluso su patriotismo habian ocasionado una serie de contradicciones, de tensiones internas en su persona, que algunos poemas anteriores habían explorado de modo más o menos oblicuo, como "Napoleon in 1814", donde aparece el tema del sometimiento a unidad de impulsos contrarios. Ahora, la disyuntiva entre la disciplina de ese sometimiento y la liberación respecto de la voluntad individual aparecía a las claras al haberse vuelto insoportable la fuerza de la contradicción. El poeta siente al mismo tiempo el impulso de resolver sus perplejidades y alcanzar la luz del día y el de preservar su oscuridad, cerrarse sobre sí mismo, de espaldas a esa luz: el viaje a ese centro que irradia el día, esa certeza absoluta a la que le impelía su acercamiento al marxismo, no se realiza sin una cierta reticencia. El movimiento es fruto de una tensión entre una fuerza centrípeta y otra centrífuga:

To break out of the chaos of my darkness Into a lucid day, is all my will.

My words like eyes in night, stare to reach

A centre for heir light: and my acts thrown

To distant places by impatient violence

Yet lock together to mould a path

Out of my darkness, into a lucid day.

Yet, equally, to avoid that lucid day

And to preserve my darkness, is all my will.

My words like eyes that flinch from light, refuse 
And shut upon obscurity; my acts

Cast to their opposites by impatient violence

Break up the sequent path; they fly

On a circumference to avoid the centre (Spender 1951, v) ${ }^{9}$.

Se trata de un poema importante para Spender, que no sólo lo incluyó en The Still Centre sino que lo introdujo como pórtico a World within World: en ese conflicto, parece sugerir por tanto, se resume el drama de su vida, y conviene reparar en que la fecha de composición que se especifica en World es 1935, es decir, antes de la militancia comunista y la decepción en España. Como el Wordsworth que al contemplar el espectáculo de los Alpes quedaba cegado por las "imágenes del gran Apocalipsis", en uno de los pasajes más representativos de lo sublime romántico, el poeta parece aqui retraerse ante una luminosidad abrumadora, más allá del umbral de la percepción, que comporta la anulación del yo. Adherirse a la causa comunista suponía algo parecido a la experiencia romántica de lo sublime.

Por si esto no bastase, a finales de 1939, cuando aparecia The Still Centre, este conflicto, anunciado ya en las crisis personales de la década de los treinta y en la confusa iniciación sexual del poeta, venía exacerbado por su violenta ruptura con Inez. Así, A. Kingsley Weatherhead $(1975,177)$ ha señalado con acierto cómo el tema de fondo del libro no es otro que "el logro de unidad del ser o la imagen de un yo integrado o completo". El mundo de los sentimientos personales y sus incertidumbres volvía para quedarse. En su diario de septiembre de aquel año Spender escribía que "el problema de las personas casadas no es lograr quedar absorbidos el uno en el otro, sino conseguir evitarlo"; al mismo tiempo, envidiaba la habilidad de su amigo Ernst Robert Curtius, a quien había tratado estrechamente en Alemania, capaz de entablar amistades auténticas y no quedar anulado por ellas. "No es que careciera de empatía -explicaba- sino que evitaba sacrificarse a sí mismo porque sabía que lo que tenía poseía demasiado valor objetivo para sí y para los demás como para sacrificarlo" (1985, 38). Para Elizabeth Mayer, la amiga judía a la que Auden dedicó su New Year Letter en Nueva York, tendría palabras parecidas. Una vez más, el tema del sacrificio articulaba la cuestión de las relaciones del individuo con el mundo, pero en esta ocasión no se trataba sólo de renunciar o no a la independencia de criterio político sino a los recovecos de la intimidad que debian dejarse a merced del otro, fuese el amigo o el amante. Como una especie de movimiento pendular, el desencanto político había empujado al poeta hacia el extremo opuesto, el intimismo.

Después de regresar de España reaccioné contra el intento de alcanzar la santidad comunista hacia una extrema preocupación con los problemas del yo. Escribí poemas en los que volvía sobre el tema de mi sensación de estar aislado en mi existencia personal, pero intenté mostrar la condición del yo aislado era la condición universal de toda existencia (Spender 1951, 254-55).

Para alguien que en aquel momento se dedicaba a traducir a Rilke, esta consideración quedaba muy cerca de la idea rilkiana del yo y de su definición del amor como "dos soledades que se rinden homenaje". En cualquier caso, ese "centro fijo" de 1939, que Spender deseaba encontrar como punto de anclaje en la existencia, personal, afectiva y política, se convirtió en una preocupación constante durante el resto de su vida. Puede decirse que se trata además de una de sus expresiones más típicas: por ejemplo, en The Creative Element esboza un revelador retrato de su amigo y gran moralista de su generación que fue E. M. Forster. Si lo característico de los individualistas visionarios como Blake era su impulso de construir todo un mundo desde su imaginación personal, como alternativa a los valores de una sociedad que rechazaban, la condición de un Forster es que "su visión tiene un centro, pero él duda de su capacidad para afectar a la circunferencia, de hecho es escéptico ante cualquier afirmación de que el centro pueda cambiar el mundo y vuelve a menudo a la idea de que no debería pretenderlo" $(1953,77)$. ¿Cabe una refutación más contundente, pero al mismo tiempo sensata, de la ideologia literaria de los treinta, aquella época en que un puñado de poetas creyeron que la letra impresa podía cambiar el curso de la Historia?

De este modo, la doctrina de no intervención dejaba de ser un término de política internacional y pasaba a designar también una actitud estética: no exactamente un ejercicio de escapismo, pero sí una decidida resistencia a dejar que la visión personal del poeta quedara absorbida por la ideología, por un lado, y una puesta en fuga de cualquier esperanza ilusoria de que el poeta pudiera incidir en la vida social y política, por el otro. "La poesía", rezaba el famoso verso que Auden escribió aquel año de 1939, "no hace que suceda nada". El escritor era cronista, espectador y, al mismo tiempo, la voz misma de los hombres: se trataba de mostrar que somos, sí, una isla, pero que 
precisamente compartimos nuestra condición insular. Esta paradoja viene expresada mejor que en ninguna otra parte en "The Human Situation", cuyo elocuente título esboza una especie de conclusión a la crisis que el poeta venía de atravesar: en una suerte de epoché de toda posición ideológica absoluta, el poeta afirma su afianzamiento en el yo como certeza única, como centro desde el que contemplar el mundo sin buscar el refugio seguro de la ortodoxia. Su debilidad, esto es, su actitud variable, escéptica, ajena a los posicionamientos dogmáticos, es al mismo tiempo su fortaleza. Soportar la incertidumbre sin atajar por el camino fácil de la adhesión a la lectura preestablecida será la tarea del poeta:

This I is one of

The human machines

So common on the grey plains-

Yet being built into flesh

My single pair of eyes

Contain the universe they see;

Their mirrored multiplicity

Is packed into a hollow body

Where I reflect the many, in my one [...]

0 legendary heroes, sailing through dreams

Looking for land when all the world was sea

And sunrise, 0 bare-kneeded captain of my first school,

0 victors of history, angry or gentle exponents

Of the body as an instrument which cuts

A pattern on the time, 0 love

Surrounding my life with violet skies,

It is impossible for me to enter

The unattainable ease

Of him who is always right and my opponent,

Of those who climb the dawn with such flexible knees,

Of those who won the ideologic victories,

Of her whose easy loving turned to flowers

The forbidden and distorted natural powers;

Impossible to imagine, impossible to wish

The entrance into their symbolic being

Death to me and my way of perceiving

As much as if I became a stone;

Here I am forced on to my knees,

On to my real and own and only being

As into the fortress of my final weakness

(Spender 1985, 53-56) ${ }^{10}$.
El título de este poema ofrece una interesante clave para comprender la evolución de las ideas de Spender tras su regreso definitivo de España: su relación con Malraux, cuya novela La condition humaine (1933) resuena en la expresión "The Human Situation". Tanto en su artículo "Spain Invites the World's Writers" como en World within a World Spender no duda en erigir al escritor francés en el "héroe" del Congreso de 1937. Dotado de una inquebrantable "confianza en sí mismo", entusiasta de un sano "individualismo liberal" en política y empujado por un afán aventurero que le llevaba a implicarse en todos los acontecimientos de la época, Malraux ofrecía un modelo de escritor que a los jóvenes de la generación de Spender no podía sino fascinar, y más una vez que había tenido lugar el desengaño político: la perfecta simbiosis de la espada y la pluma, pero sin la servidumbre literaria a la ideología.

De hecho, Malraux había recorrido territorios parecidos a los de Spender con diez años de antelación y habia dejado sus huellas en forma de ensayos como La tentation de l'Occident (1925) y novelas como La vie réel (1930) - la propia La condition humaine, que recreaban sus experiencias en China y Camboya, adonde había acudido inicialmente en 1923 con su esposa Clara Goldsmith para robar piezas de arte oriental. Por ejemplo, esta última novela comenzaba con la famosa escena en la que el activista revolucionario Chen, al acercarse a la víctima a la que se apresta a asesinar, descubre en sí mismo "no al combatiente que conocía, sino al sacrificador". Luego, durante una reunión de la célula comunista en la que organizan el sabotaje, cuando uno de sus miembros advierte que los guardias blancos fusilan a la población en represalia, Kyo, el jefe de la célula, deshace la objeción con una simple declaración de cinismo: "Nosotros también fusilamos, camarada". En suma, la novela de Malraux describía la crudeza de aquella cultura del sacrificio y las contradicciones éticas a las que debía hacer frente toda intentona revolucionaria, con una lucidez que a Spender no podía dejar indiferente. En las últimas páginas, tras la muerte de su hijo, el padre de Kyo declara que "el marxismo ha muerto en mí", que "todo es en vano", y descubre que más allá de la revolución hay "mundos de contemplación", en un movimiento anticopernicano de la conciencia gemelo del que experimenta Spender. Contra la fe en la indefinida perfectibilidad del mundo mediante la acción política y la intervención del individuo en la Historia, se afirma ahora una actitud quietista 
en la que lo más real de todo es la inmutabilidad de lo sustancial:

Lo crucial aquí es que ese era precisamente el credo que había guiado a la generación de Spender más allá del cómodo redil de su conciencia burguesa. "Mi problema -explica en las últimas páginas de World within a World- era conectar mi mundo interior con alguna actividad exterior". Con el ejercicio de introspección de "The Human Situation", el poeta parecía inaugurar una etapa de meditación semejante a la que acometía el personaje del padre de Kyo: después de aquella pesadilla de la militancia política, la guerra, etc., en suma, después de aquel intento de unir al hombre con los acontecimientos del universo, lo único que quedaba era el yo. Un yo que "refleja a los muchos en el uno" y se constituye así en una suerte de centro del mundo, pero un yo caracterizado como órgano de percepción que, con todos sus errores y vacilaciones, se afirma como la única roca a la que asirse. De la política a la ética, la autoconciencia recién conquistada impide al poeta adoptar el cómodo dogmatismo "del que tiene siempre la razón", de los que "ganan las victorias ideológicas". Aquella promesa de una certeza infalible quedaba desvanecida con el desengaño político pero, como rezan los últimos versos de "The Human Situation", el poeta es capaz de convertir esa debilidad en una fortaleza. 0 , dicho de otro modo, de mostrar que aquella aparente fortaleza ocultaba la miseria de la debilidad, la incapacidad moral de tomar una postura abierta ante la Historia y la tentación de refugiarse en los juicios aprioristicos según el dictado de la ortodoxia.

La huella de Malraux se deja sentir aqui y allá en muchas consideraciones de Spender de aquella época. Por ejemplo, en la inversión de los términos de la estética del compromiso: en La tentation de l'Occident Malraux había escrito que los occidentales "apenas comprendemos que para ser no hace falta necesariamente actuar y que es el mundo el que actúa sobre nosotros, más que nosotros quienes lo transformamos". ¿No equivale esto a la idea de World within a World de que el escritor moderno era alguien que utilizaba sus impresiones "más para cultivarse a sí mismo que para actuar sobre el mundo"? El descubrimiento de la conciencia, de aquellos "mundos de contemplación" que sacaban al escritor de su progresismo ingenuo a la hora de enfrentarse a la Historia, comporta un diagnóstico sobre Occidente, que Malraux describe en efecto como una civilización enferma de acción por contrapunto al carácter más contemplativo de las filosofías de Oriente. Pero esto no implicaba en su caso una pura impasibilidad ante los acontecimientos: la tarea del escritor es precisamente dejarse afectar por esos acontecimientos. El retrato del escritor francés que Spender bosqueja en "Spain Invites the World's Writers" resume todo el replanteamiento de estas cuestiones -el héroe, el papel del individuo en la Historia, la importancia de la leyenda personal, el foco irrenunciable de la conciencia- casi como si estuviera pensando en el proyecto de sí mismo, en el escritor en que soñaba convertirse. Así recuerda las palabras de Malraux durante sus largas conversaciones:

El escritor debe crear desde un centro que es su entorno; y a veces sucede $-y$ ha sucedido repetidamente con los escritores de esta generación-, y esa es sin duda la raíz de su interés por la política- que en escritor no encaja en su entorno. Entonces se verá obligado a descubrir otro entorno o, si es un individualista exacerbado, a crear uno enteramente propio. Debe crearse un mundo y luego crear literatura a partir de su leyenda personal [...] Si me preguntas qué hay que hacer, la res puesta es /I faut agir (Spender 1978, 52).

Había que actuar, sí, y Malraux lo hizo como nadie con su escuadrilla de aviación de L'Espoir, pero también con una independencia que le permitió quedar bajo las órdenes directas de Hidalgo de Cisneros y administrar aquel cuerpo de aviadores voluntarios "con un espíritu liberal", como decía él. El rechazo del marxismo como doctrina política no era una invitación a la pasividad o la resignación, no arrojaba al individuo fuera del cauce de la Historia. ¿Por qué? Porque aquel impulso reflexivo, aquel movimiento centrípeto que Spender había representado en "Darkness and Light", era sólo un momento inicial de la conciencia, que no podía quedar perpetuamente replegada sobre sí misma. Como en una sucesión de ondas concéntricas, debía hacerse cargo de ámbitos de la realidad progresivamente 
más amplios. Ya no se trataba de una disyuntiva perfecta entre el nosotros y el yo, como había sentido su generación durante la década de los treinta, sino de un camino por el yo hacia el nosotros, o al todos: la solidaridad con el otro no pasaba por el sacrificio del yo sino que tenía lugar desde el yo mismo, como si toda la humanidad se reflejase en cada hombre, en un nueva muestra de que el mejor anclaje para el liberalismo político era una psicología y una ética kantianas pues, como señaló Hannah Arendt $(1994,181)$, para el regiomontano "la esencia del hombre consistía en que cada ser humano individual representaba toda la humanidad". Así, tal como enuncian los primeros versos de "The Human Situation", el poeta puede declarar que "yo reflejo a los muchos en mi uno".

Es significativo que, en September Journal, Spender caracterice como romántica esta idea de que "mi situación como ser humano individual puede contener implicaciones que alcancen al conjunto de la vida contemporánea" (1985, 46). El trabajo del escritor, así, consistiría en percibir el mundo desde ese centro de su propio yo, en la confianza de que esa percepción puede arrojar una luz a los demás 0 , como dice en "Spiritual Explorations", de que "soy el testigo a través del cual el todo sabe que existe". De la política a la ética, del todos al cada uno, de la arenga al susurro, la voz del poeta se erige en la del hombre mismo: el yo no monologa en una soledad pura, habla a otros yos, pero tampoco perorea ya ante una multitud anónima, en una senda que cabe calificar como romántica". En "From Poetry to Politics", un texto escrito precisamente en 1937, cuando a su vuelta de España Spender revisaba sus ideas sobre la relación entre poesía y política, explicaba que aquélla puede tratar los temas de ésta, sí, pero precisamente porque es "en la conciencia de muchos individuos separados donde tiene lugar el debate político" $(1984,41)$. De hecho, la idea de romanticismo que Spender ofrece en The Struggle of the Modern es muy determinada: la del poeta que se pone a sí mismo en "el centro del universo" $y_{1}$ al hacerlo, erige a la imaginación en "centro transformador de la conciencia poética". Es más, a renglón seguido Spender advierte que, pese a las reacciones contemporáneas contra el romanticismo, la poesía y la crítica moderna han asumido la idea de la imaginación como "centro" en el que convergen las experiencias y desde el que el artista crea su mundo. Ya no era preciso renegar de sus raíces románticas para reconciliarse con el presente y adjudicar alguna función social al escritor.

\section{El CANTO dEL CRONISTA}

Con consideraciones de este tipo, Spender remonta una senda que se desvía significativamente del camino que su generación había trazado en un principio, y que sus dos mejores amigos -Auden y Eliot- habian señalado con insistencia. Porque ¿qué supone esa metáfora del centro, esa idea de la imaginación romántica, sino un intento de restituir a Coleridge y a Wordsworth? De hecho, si se lee entre líneas no es difícil encontrar una presencia intermitente de los poetas de los lagos en el mundo de Spender: como ya he comentado a propósito de "A First War Childhood", el poeta refería el origen de su conciencia a una anécdota reinterpretada a la luz de Coleridge; en World within a World comenta cómo, pese a que el intento de escribir una poesía monumental le inspiraba rechazo en piezas como "Ode on the Intimations of Immortality", los poemas de Wordsworth sobre las gentes marginales, vagabundos y fuera de la ley le habían seducido de adolescente. Además, de niño había pasado varios veranos en la granja familiar en el Distrito de los Lagos, su padre le había leído poemas de Wordsworth como "We Are Seven" y "A Lesson to Fathers", cuyas palabras "habian caido en mi mente como piedrecillas, brillantes y puras", y aquella voz leyendo a su madre los poemas más largos como The Prelude había quedado en su memoria como símbolo "del misterio y el placer de la poesía". Setenta años después, en "Worldsworth", todavía recordaba en un poema de más de cien versos aquellas tempranas lecturas de 1916: si había un nombre que podia servir como epitome de la figura sacralizada del poeta, investido de una imaginación que al adherirse a la Naturaleza creaba un mundo, ese era Wordsworth. En su lectura, en su nombre mismo, Spender parecia localizar el origen de su conocimiento del mundo y de su vocación poética. "Rhythms I knew called Wordsworth / Spreading through mountains, vales, / To fill, I thought, the world. / 'Wordlsworth', I thought, this peace / Of voices intermingling- / 'Worldsworth', to me, a vow" (Spender 1994, 40-41) ${ }^{12}$.

Esta restitución ética y poética de la figura de Wordsworth en Spender supone, por tanto, un aspecto más de ese acto de sinceramiento consigo mismo: el poeta de The Prelude era parte de su vida, de su mundo, de su propia conciencia. Pero, además, su recuperación contenía en aquel momento tres virtualidades que conviene subrayar. En primer lugar, su poética de la imaginación, aquella omnímoda centrali- 
dad del yo que Keats había designado como el egotistical sublime, suponía el precedente más claro de su propia comprensión del modernismo, aquella literatura en la que "el mundo exterior se convierte en un mundo interior dentro de la mente del individuo", como expresaría en World within a World. En segundo lugar, la idea de que ese yo es capaz de afectar y verse afectado por otros ponía al poeta a salvo de todo solipsismo, una amenaza que escritores como D. H. Lawrence advertían en el modernism y que el propio Spender confesaba que no era su propia idea de la condición del poeta. En tercer lugar, ante el conflicto de la guerra la figura de Wordsworth suponía una alternativa al modelo del mártir que encarnaban Cornford, Fox, Bell, etc.

De hecho, en World within a World Spender contrapone directamente el "martirio" de aquellos jóvenes con la actitud de un Wordsworth que, "en una situación paralela" -es decir, durante su estancia en la Francia revolucionaria- sintió "que su deber era sobrevivir y dar testimonio" $(1951,203)$. Contra los que sometieron su talento a la causa política, que se reveló "demasiado exigente", lo que se necesitaba para dar cuenta de los acontecimientos era más bien "la pasión individual que pudiera representar los tiempos en la experiencia personal". El escritor debía relatar los hechos, no aspirar a conducirlos: el hombre de letras y el hombre de acción eran individuos distintos. Merece la pena reproducir el fragmento de The Prelude que Spender cita para ilustrar esta inspiración de Wordsworth en aquellas procelosas circunstancias. Se trata de los versos 209-235 del libro X de The Prelude, "Residence in France (Continued)", en los que, tras señalar el mérito histórico del pueblo francés de recorrer el camino que va de la oscuridad a la luz pese a los siglos de ignorancia y la oposición de las fuerzas exteriores, el poeta refiere su salida del Continente:

In this frame of mind,

Dragged by a chain of harsh necessity,

So seemed it, -now I thankfully acknowledge,

Forced by the gracious providence of Heaven,-

To England I returned, else (though assured

That I both was and must be of small weight,

No better than a landsman on the deck

Of a ship struggling with a hideous storm)

Doubtless, I should have then made common cause

With some who perished; haply, perished too,

A poor mistaken and bewildering offering,-
Should to the breast of Nature have gone back,

With all my resolutions, all my hopes,

A poet only to myself, to Men

Useless, and even, beloved Friend! A soul

To thee unknown! (Wordsworth 1994, 721) ${ }^{13}$.

Se trata de un episodio conocido y de amplias resonancias para el lector de poesía inglesa, pues supondría un punto de inflexión en la trayectoria de Wordsworth: el paso de la Revolución a la Naturaleza, de la acción a la escritura, el acceso del joven amigo de los jacobinos y entusiasta de la revolución a una madurez que lo conduciría paulatinamente hacia el remanso de un notable conservadurismo, una tibia adhesión a la Iglesia de Inglaterra y un tardío reconocimiento como laureate poet. En una palabra: a su reconciliación con el establishment, que los jóvenes de la siguiente generación interpretarían como un acto de alta traición a los ideales revolucionarios. Así, en "To Wordsworth", un airado e irreflexivo Shelley expresaba la decepción que había experimentado al visitar al que él creía un héroe de las libertades. Él, que había sido "como una estrella solitaria" que guiaba al poeta adolescente, al abandonar sus cantos "a la verdad y la libertad" dejaba desolado a su joven admirador.

En el contexto del relato autobiográfico de Spender sobre sus andanzas en España, su crisis de conciencia política y su resolución, este fragmento de The Prelude sugiere un paralelismo muy rico y de un signo completamente distinto al que adquiere en manos de Shelley. En primer lugar, nos recuerda el hecho decisivo de que, como sucede con Wordsworth, los poemas de Spender sobre la guerra de España no están escritos a pie de trinchera sino desde una óptica retrospectiva, cuando el poeta ha abandonado el escenario de los acontecimientos, en un ejercicio de "emoción recordada en la tranquilidad", según la conocida fórmula del prefacio a las Lyrical Ballads. Y ese ejercicio de distanciamiento no es sólo físico: la busca de una cierta ecuanimidad, tras el descrédito de las actitudes banderizas que habia acarreado su desencanto político, suponía para el poeta un problema de índole ética y poética, el de dar con un tono adecuado para recrear su experiencia de la guerra.

En segundo lugar, el requisito experiencial, la contemplación del mundo desde el centro del yo y no desde el sol de la ideología que deslumbraba al poeta en "Darkness 
and Light", es idéntico del que supone la escritura de Wordsworth: en una suerte de empirismo literario, que oculta una desconfianza hacia toda actitud aprioristica, la literatura tanto de Wordsworth como de Spender se vuelve marcadamente autobiográfica. Lejos de la épica y de la propaganda, lo que encontramos en sus poemas sobre España es el relato de una serie de experiencias, fundamentalmente: como para Wordsworth, cuyo Prelude llevaba por subtítulo "El desarrollo de la mente de un poeta", se trataría de una vivencia iniciática en la que el poeta intenta reconocer desde el presente los jalones que en el pasado le han conducido a su ser actual, en ese itinerario en el que casi cabe entrever la mano de la Providencia, como sugiere el fragmento.

En tercer lugar, ese papel de la Providencia -o de la fatalidad, o del azar, o de lo que se quiera- supone una obvia expresión de alivio y un juicio muy determinado: el poeta celebra no haberse sumado a la causa hasta el punto de perecer, como lo han hecho otros, en un sacrificio "desconcertante y equivocado". Una afirmación que, a la luz del párrafo precedente, en el que Spender trata la cuestión de los mártires británicos en la guerra española con nombres y apellidos, comporta una actitud ética decidida: una confrontación con la cultura del sacrificio que auspiciaban los ideólogos como Pollitt.

En cuarto lugar, el fragmento contiene solapadamente una autojustificación no ya ética sino poética: el poeta regresa a Inglaterra consciente de que él mismo "pesa muy poco", igual que cualquier otro paisano sobre la cubierta del barco contra la tormenta, es decir, de que su capacidad como escritor de influir en el rumbo de los acontecimientos revolucionarios es muy escasa, lo mismo que cualquier otro ciudadano, en una imagen que contradice el credo de la estética del compromiso en la generación de Spender. Y la expresión de alivio de Wordsworth por no haber sucumbido en Francia cobra un significado muy concreto: el cometido de su existencia es ahora escribir su obra, "ser" poeta y darse a conocer a los demás, como al "amigo" al que va dirigido el largo poema de The Prelude y al que aquí se apostrofa, que no es otro que Coleridge. De este modo, un Spender desconcertado se apoya en Wordsworth para cobrar fuerza y dar un salto hacia delante, en una beneficiosa anxiety of influence: la tarea del poeta no consistía en ofrecerse en holocausto sino en "sobrevivir y dar testimonio", una resolución que parece inaugurar una nueva vida para el joven Spender; el lema de Malraux, il fau agir, del que se hacía eco, no implicaba ya una disyuntiva perfecta entre vida y literatura, o entre acción y escritura, sino que venía a traducirse en la conciencia de que la escritura puede constituir una forma de acción de efecto diferido. Pero esto no debía llevar a confusión a nadie.

La poesía no tiene que ver con la acción sino con las fuentes vitales de las que brota la necesidad de la acción. Cuando afirmo que la poesía moderna es política, no estoy penando en un John Cornford que abandona la poesía para luchar contra los fascistas en España, sino en el hecho de que los mejores poemas de Hardy, los poemas de la guerra de Wilfred Owen, The Waste Land de Eliot y gran parte de la poesía de Auden trata el tema del individuo que se enfrenta a una crisis de la civilización sin precedentes [...] Por mucho que admiremos las acciones de John Cornford o un Rupert Brooke, la poesía no es lo mismo que la acción y un poema no es lo mismo que una tesis política $(1984,42)$.

\section{Confesión y APOLOGÍA}

La presencia de Wordsworth en Spender es, por tanto, muy rica. Que el relato autobiográfico sea iniciático, que nos muestre el encuentro del sujeto con el mundo y el autoconocimiento que de ese encuentro obtiene y que esa historia se constituya en "Preludio" del resto de su vida son rasgos que invitan a considerar World within a World como dentro de subgéneros bastante determinados: la confesión y la apología. Conviene tener en cuenta la precocidad del relato, escrito cuando el autor contaba apenas cuarenta años de edad y cuando le restaban aún cuarenta y cinco de vida: tras haber sobrevivido a dos guerras y dos matrimonios, haber atravesado experiencias imprevisibles y variopintas, se abría el panorama de una nueva vida, en un mundo también nuevo. Así, World parece sugerir una necesidad de arreglar cuentas con un pasado muy determinado, una necesidad íntima pero también de índole pública: el poeta que se esforzaba en buscar acomodo dentro del escenario de la Guerra Fría se sentía impelido a explicar su juvenil militancia en un comunismo que constituía ahora el mayor de los enemigos. De hecho, esa centralidad del yo que reivindicaba su relato podía interpretarse fácilmente en clave política, como un ejercicio de neutralidad o equidistancia, y el propio Spender dio pábulo a este tipo 
reinterpretaciones cuando declaró que no estaba "ni con el Este ni con el Oeste, sino conmigo mismo considerado como un yo": lo que el derrumbe de las interpretaciones absolutas y tajantes traía consigo, antes que nada, era la obligación moral de sopesar las opciones desde ese centro de conciencia, que ya no se hacía cargo de las cosas anulando la experiencia individual. Como si temiera quedar enfangado, preso de una objetividad pura como la de aquel marxismo que había abandonado, conforme la narración de World within a World se acerca al momento de su escritura se va haciendo más parca, más reticente, más elusiva, recordándonos que la subjetividad no puede objetivarse del todo, que el sujeto debe reservarse siempre la posibilidad de evitar la respuesta definitiva, que le asiste el derecho a desdecirse de sus afirmaciones y arrojar sobre ellas la sombra de la provisionalidad.

Las últimas páginas de World within a World desarrollan una larga reflexión sobre esta última idea, en lo que supone una auténtica disquisición sobre el propio género de la autobiografía. ¿No habría sido mejor, empieza preguntándose el autor, escribir todo esto en forma de novela? Así se habría evitado la inmediatez, el impudor de que el autor se identifique con el protagonista, que tanto espantaba a Auden en aquella conversación veneciana. Pero "yo soy yo", se responde Spender, y la ficción autobiográfica ofrece "avenidas de escape" que permiten huir de la autoconciencia luminosa del que sostiene ese enunciado tautológico: el autobiografismo de Spender parece apuntar, así, en la dirección de una "sinceridad" romántica. Ahora bien: ¿cuál es el contenido predicativo de esa tautología? ¿Quién es ese yo? Ése es precisamente el tema del relato y de su propia vida, afirma Spender, pues lo que buscaba en Alemania, en España, etc., no era otra cosa que "descubrir mi yo real mediante actuaciones que pusieran a prueba a mi yo ideal". Es decir, que, en una suerte de proyección de una forma a priori sobre la materia existencial cruda, Spender entiende su propia vida como una autobiografía, como una quest en busca de su identidad personal.

Algo subsiste de freudiano o de gidiano en este empeño, en la medida en que Spender explica que esa búsqueda acontece no sobre un plano exento de obstáculos, sino bajo la forma de una esforzada exhumación: para dar con el yo había que ir retirando las sucesivas capas de ocultamiento, en un proceso que cabe relacionar con la rebelión del joven Spender contra lo que él llamó la "decadencia puritana" en que se había formado, y que con frecuencia se mostraba como una forma de hipocresía victoriana. Si algo le exasperaba desde pequeño, comenta en ese largo epílogo a su autobiografía, era la actitud "insincera" de los que encerraban en convenciones las experiencias únicas y personales, se negaban a aceptar su soledad espiritual y sus miedos y aprendian de sus padres "a no hacer preguntas". De este modo, la búsqueda de World within a World desarrollaria también una suerte de autopsicoanálisis, en el que esa identidad personal "auténtica" y no evidente sólo se conoce tras despejar los sucesivos engaños de los que la conciencia ha sido objeto.

El principal de esos engaños históricos, sostiene Spender, habia sido el "comunismo" de origen marxista, que le había hecho creer que era "un simple producto de mis circunstancias burguesas" y que constituia un error pensarse a sí mismo "separado de la sociedad". Una herencia del lenguaje de Hegel, para quien lo abstracto era lo aislado, lo separado del todo, y lo concreto sólo la imagen de la totalidad. "La esencia humana", había afirmado también Marx en su sexta tesis sobre Feuerbach, "no es una abstracción inherente al individuo aislado. Es, en su realidad, el conjunto de las relaciones sociales". Es decir, que por un lado se evitaba la reducción del hombre a un conjunto de rasgos abstractos, obtenidos de una consideración esencialista y proyectados sobre el individuo, que sería así una mera realización particular de la especie, pero por el otro se tomaba al hombre como un simple producto social e histórico, en una ecuación inamovible. Las relaciones sociales crean al individuo, en una lógica que autores como Adam Schaff $(1978,112)$ han denunciado en la medida en que delata la proclividad de algunos pensadores marxistas a obviar la realidad radical del individuo $y$, en último término, a formular sus ideas desde un espíritu idealista que falsea el planteamiento materialista del propio Marx.

De hecho, más que un engaño, el marxismo como epistemología suponía aquí un sencillo escamoteo del problema: ante la pregunta por la identidad personal, se negaba la existencia de tal cosa, porque el individuo y la subjetividad individual en cuanto entidades concretas desaparecian dentro de un monismo riguroso. No había ya un ámbito de intimidad ajeno a las relaciones económicas, que además actuaban sobre la vida siguiendo un determinismo irremisible. La única entidad concreta era la colectiva -fuese 
la clase, el Partido o el Estado- y lo único que contaba era la causa, a cuyas exigencias todo debía sacrificarse. Con su aversión al empirismo burdo de su época y sus pretensiones sistémicas, Marx había elevado a virtud el miedo al contacto de la deducción lógica con la realidad empírica. Ahora, en manos de la generación de Spender y del lenguaje de la propaganda, esta tendencia derivaba en una nueva forma de abstracción que permitía enviar a cientos de individuos concretos a la muerte y mirar hacia otro lado: el de un futurible de perfección ontológica, un estadio suprahistórico de la Humanidad.

Una de las virtudes de la escritura autobiográfica, apunta Spender, es precisamente que despeja también esa ilusión: si se producen las guerras y las revoluciones, argumenta, es porque se hacer creer a la gente que pueden alcanzarse objetivos como la aspiración comunista a ese día en el que la Dictadura del Proletariado hará cesar todo conflicto. Pero esta lógica utopista, que bajo su pretensión desmesurada esconde una auténtica secularización de lo escatológico, sólo puede causar frustración, ya que ese horizonte no llega nunca a vislumbrarse, no digamos ya a alcanzarse en la Historia. Y esto se muestra a las claras en la autobiografía: el gran hallazgo del relato de Spender es precisamente que "la dirección lo es todo", puesto que "vivimos en el tiempo y nunca estamos completos". La temporalidad, así, no forma parte accesoria de nuestro modo de existir sino que la constituye, y la estructura narrativa de la vida humana apunta hacia un horizonte que siempre queda más allá de nuestro alcance. En otras palabras, ese estadio de perfección no existe ni existirá porque siempre seremos perfectibles: sin necesidad de hacer suyas las ideas de un Heidegger y su Sein und Zeit, Spender advierte que la propia idea de perficio, de acabamiento, contradice la historicidad y la temporalidad de nuestro ser, y que la empresa de forzar las cosas no sólo está condenada al fracaso sino que produce cuantiosas bajas por el camino. En suma, la propia narrativa autobiográfica empuja a readmitir una visión liberal de la Historia al estilo de un Popper o un Berlin, en la que los procesos no pretenden alcanzar su propia cancelación. No es casual, por tanto, que World within a World esté dedicado a Isaiah Berlin, que por su infancia en la Riga de los años diez y veinte conocía la deshumanización de la vida que comportaba el comunismo ${ }^{14}$ y que en las décadas posteriores desarrollaría una brillante defensa del liberalismo contra el pensamiento totalitario.
Lo fascinante de estas conclusiones es que, al rechazar la visión abstracta, ideológica y ahistórica y optar por el discurso de lo concreto, lo subjetivo y lo experiencial como punto de partida, Spender muestra las posibilidades de una nueva epistemología, alternativa a la idea holística del marxismo. La conclusión principal de World within a World es, sí, que "existe el deber de luchar por la preeminencia de la conciencia individual", que "lo público es necesario, pero lo privado no debe verse abolido ni el individuo devorado por el concepto del hombre social" $(1951,312)$ y que el principio de todo conocimiento real es aceptar "que uno es una existencia aislada y que dentro de sí está el mundo de su propia alma, tan vasto como el universo" $(1951,334)$ Con Coleridge, Thomas Browne y un largo etcétera, Spender entona un nuevo Nosce te ipsum como principio de todo conocimiento. Si la pregunta que acuciaba su mente a mediados de los treinta era cómo debía concebirse a si mismo el individuo para un mundo comunista, a partir de su experiencia española y su abandono del Partido la cuestión será cómo concebir el mundo para un individuo libre.

Evidentemente, esta ansiosa necesidad de defender los derechos de la vida individual sólo se entiende a la luz de los intentos totalitarios del siglo XX y su maquinaria de control, que tanto preocuparía a compañeros de generación de Spender, como George Orwell. Pero esta conclusión se establece a través del propio relato, que no deja de examinarse a sí mismo: el regreso a la vía del autoconocimiento, en una suerte de intimismo que recupera el mandato de Delfos, no es todo lo inocente que pudiera parecer, porque Spender permanece consciente de que el conocimiento es fijo y su objeto móvil, y de que "la idea estática de uno mismo basada en la aceptación de la experiencia pasada" incurre en autoindulgencia. Y para alguien que piensa que la memoria es la principal facultad del poeta, en un rasgo más de filiación wordsworthiana, esto es tanto como reconocer la ficcionalidad, la indole constructiva del relato autobiográfico: el acontecimiento pasado se convierte en el mito presente, porque sólo el mito puede articular los recuerdos aislados y proporcionar la imagen total.

El problema es que esa imagen se completa en el último párrafo de World within a World. "El hecho", afirma a propósito de unos recuerdos infantiles, "sigue siendo que soy y era la misma persona", en una consideración flagrante- 
mente ahistórica que nos lleva a pensar en una identidad original, de filiación romántica, a la que los acontecimientos le son de algún modo ajenos, o al menos a la que no se le ha arrebatado la posibilidad de filtrar y modular los estímulos procedentes del mundo histórico, según la conocida propuesta de Fromm: un yo que delimita su territorio y conserva cierta soberanía sobre sí mismo. Al rondar una y otra vez el enunciado tautológico -"yo soy yo"- Spender delata una idea hipostática del yo, una subjetividad abisal, que en último término siempre permanecerá inasequible al lenguaje, incluso al cabo de trescientas páginas de narración, en lo que se presenta como una refutación de la tesis marxista de que el individuo sea un mero producto histórico. Su amigo Auden podía estar tranquilo: el desvelamiento no podía quedar completo, la propia verbalidad comportaba un cierto pudor.

\section{NOTAS}

1 Es mía la traducción de las citas cuya referencia aparece en inglés o francés en la bibliografía.

2 En el momento en que Spender publica su autobiografía esta cuestión -la de si el marxismo llevaba dentro de sí la semilla del totalitarismo o este era un desarrollo adventicio que dependía de un cúmulo de circunstancias añadidas a la ideología- estaba sujeta a debate. Puede decirse que la tesis de fondo de Animal Farm, la conocida novela de Orwell, era que el stalinismo suponía una traición al espíritu original de la revolución; en cambio, al año siguiente de publicarse World within a World, Waldemar Gurian publicó Bolshevism: An Introduction to Soviet Communism, donde establecía una secuencia lineal de Marx a Lenin y de este a Stalin. Lejos de un traidor a los principios del marxismo, Stalin sería su ejecutor más destacado.

3 El Enquiry Concerning Political Justice hacía uso de una psicología empirista radical, una antropología en parte rousoniana y una lógica necesitaria para negar la idea de libertad individual y establecer la doctrina de la "necesidad moral": los hombres eran producto de sus circunstancias. Al defender, en el capitulo XXIV, la disolución del Gobierno y la aboli- ción de la propiedad privada, Godwin se convirtió en un lejano precedente de actitudes revolucionarias de corte anarquista como las que proliferaron en los primeros meses de la Guerra Civil.

4 "Se trata, por supuesto, de situarse I fuera del ámbito que comúnmente I se conoce como 'estadisticas'. Han muerto / cien en la periferia. Bien, uno continúa / mientras el 'yo' se siga sosteniendo / sobre la cama, que parece un coche fúnebre, / en un cuarto de hotel donde el papel de la pared / esboza unas guirnaldas de rosas sobre el humo; / uno puede ignorar el peso de esos nombres I que el mecanógrafo ha sangrado en los periódicos / y la radio del bar aúlla aparte. / Pero ¿y si la nariz de alguna bomba / diese en la cama al fin, conmigo en ella? / Es una idea obscena, pero a muchos / la pérdida de uno les demostraría / el propio tono 'impersonal'. Lo esencial es / que ningún yo debe quedar aislado / bajo las rosas, y que nadie debe / sufrir por su vecino. Así el horror / se distribuye en cuotas hasta que deposita / en él esa guirnalda de pena incompartible / que es toda ella un misterio o nada".

5 Charles Madge, nacido en Sudáfrica en 1912, había estudiado en Cambridge y llevaba la revista Mass Observations. Además de gozar de una
Recibido: 14 de febrero de 2009

Aceptado: 23 de abril de 2009 
reputación de promiscuo y rompematrimonios, era un estalinista ortodoxo y había reseñado desfavorablemente Vienna, el poema político de Spender, de modo que reunía todos los elementos necesarios para desagradar a nuestro poeta.

6 Es curioso advertir cómo en el origen de los experimentos narrativos el modernismo se sumaría la influencia de los dos hermanos James: la de William james, que en sus Principles of Psychology (1890) había acuñado la expresión "corriente de conciencia" para caracterizar el flujo ininterrumpido del pensamiento en la mente; $y$ la de Henry James, cuyas novelas encerraban un colosal esfuerzo de estudio psicológico, hacia una intimidad abisal de sus personajes. $Y$ no debe olvidarse que una de las consecuencias de la palinodia de la generación de Spender fue su revisión de algunos elementos de su canon literario: Auden y él mismo habian tenido palabras de desprecio hacia James como ejemplo supremo de una actitud "turriebúrnea", resumido en su frase de que es el arte quien hace interesante la vida, tan contrario a una estética del compromiso. Durante los años cuarenta y cincuenta, sus novelas terminarian por ser objeto de cierto aprecio por parte de ambos poetas, aunque por razones diferentes.

$7 \mathrm{Al}$ parecer, fue Eliot quien sugirió el título. En las primeras entradas de September Journal, Spender refiere cómo el inicio de la Segunda Guerra Mundial hacia que el mundo pareciera "un desierto" en el que "no hay ya fe ni hay ya causa alguna", al volatilizarse las ideas de patria y de revolución. "Es importante -le dijo Eliot en una comida- que el mayor número posible de escritores permanezcan ahora en una actitud distante".
8 Pasada la marea de los treinta, ese sería más o menos el veredicto de la crítica de la izquierda ortodoxa sobre el llamado "grupo de Auden" en su conjunto. Randall Swingler escribía en 1941 que se trataba de una literatura "adolescente", técnicamente precoz pero "absorbida por la posición del yo en el mundo" (ver Scarfe 1942, 38).

9 "Salir del caos de mi sombra a un día / resplandeciente, es cuanto yo deseo. / Como ojos en la noche, mis palabras / buscan un centro que es la luz; mis actos, / dispersos por una violencia ansiosa, / se reúnen y forman un camino / que de la sombra sale a pleno día. / Pero también deseo preservar / mi sombra y evitar la luz del día. | Mis palabras, como ojos que rehuyen I la luz, se encierran en la sombra, y cada / acto mío, enfrentado a su contrario, / interrumpe el camino y alza el vuelo / en círculos que evitan siempre el centro".

10 "Este yo es uno / de los artificios humanos / tan comunes en las llanuras grises / pero, una vez construido en carne, / mi único par de ojos / contiene el universo que contemplan. / Su reflejada multiplicidad / la contiene un cuerpo vacío / en el que yo reflejo a muchos, en mi uno [...] ¡Oh, héroes legendarios, caminando entre sueños I en busca de una tierra cuado todo era mar! / ¡Oh, capitán de desnuda rodilla de mi escuela! / ¡Oh, vencedores de la Historia, ejemplos iracundos I del cuerpo como un útil que secciona / un modelo en el tiempo! ¡Oh, amor / que rodea mi vida con cielos violeta! / Me es imposible entrar / en la calma inalcanzable / del que tiene razón siempre y es mi oponente, / de aquellos que trepan por la aurora tan ágiles, / de los que vencieron en la batalla ideológica, / de aquellos cuyo amor trocó en flores / las facultades naturales prohibidas y distorsionadas. / Me es imposible imaginar o desear la entrada en su ser simbólico, / que es para mí la muerte y mi modo de percibir, / tanto como si fuese una piedra. / Aqui caigo yo de rodillas / en mi propio, real y único ser, / fortaleza de mi debilidad final".

11 Es significativo que Spender, que había partido e Shelley, llegase a esta conclusión, que reedita la noción empática de imaginación en Shelley.

12 "Conocí ritmos que se llamaban Wordsworth / y se extendian por los m ontes, los valles, / para llenar, pensaba yo, el mundo. / 'Worldsworth', me dije, esta paz / de voces que se entremezclan. / 'Worldsworth', una promesa para mi"

13 "Con estas ideas en la mente, / llevado por una cadena de estricta necesidad, / así me pareció -pero ahora reconozco agradecido / que fui obligado por la Providencia- / regresé a Inglaterra, pues si no (aunque seguro / de que era y debía ser de muy poco peso, / no mucho más que cualquier paisano en la cubierta / de un barco que luchara con una terrible tormenta) / sin duda habría hecho entonces causa común / con algunos que murieron, y murieron felices, en un sacrificio desconcertante y equivocado, / y habría regresado al seno de la Naturaleza / con mis resoluciones, mis esperanzas, / poeta sólo para mi mismo, y para los hombres / inútil, a incluso, amigo mío, un alma / desconocida para ti".

14 En un relato breve de 1922, "El fin justifica los medios", Berlin refiere cómo fue testigo del asesinato de un policia por un grupo de revolucionarios, en una experiencia que le inoculó un definitivo pavor a las utopías debido a la lógica que revela el título. 


\section{BIBLIOGRAFÍA}

Arendt, Hannah (1994): Essays in Understanding, Nueva York: Harcourt Brace \& Co.

Berlin, Isaiah (1998): Dos conceptos de libertad y otros escritos, Trad. Ángel Rivero, Madrid: Alianza.

- (2006): Political Ideas in the Romantic Age, Princeton: Princeton University Press.

Crossman, Michael (ed.) (1952): El fracaso de un ídolo. Trad. Luis Andrés y Frutos. Buenos Aires: Unión de Editores Latinos.

Cunningham, Valentine (1988): British Writers of the Thirties, 0xford: Oxford University Press.

David, Hugh (1992): Stephen Spender: A Portrait with a Background, Londres: Keinemann.

Garaudy, Roger (1966): Lecciones de filosofía marxista, Trad. Luis Ramón Maroto, México DF: Grijalbo.

Godwin, William (1978): Enquiry Concerning Political Justice, Harmondsworth: Penguin.

Hamilton, Ian (1994): "Stephen Spender's Lives", The New Yorker, 28 febrero.

Koestler, Arthur (1937): Spanish Testament, Londres: Gollancz.

- (1995): La escritura invisible, Trad. Alberto Luis Bixio, Madrid: Alianza.

Lagdon-Davies, John (1937): Detrás de las barricadas españolas, Trad. Guillermo
Labarca, Santiago de Chile: Empresa Letras.

Lee, Laurie (1991): A Moment of War, Nueva York: The New Press.

Leeming, David (1999): A Life in Modernism, Nueva York: Henry Holt \& Co.

Lewis, Cecil Day (1960): The Buried Day, Londres: Chatto \& Windus.

Malraux, André (1946): La condition humaine, Paris: Gallimard.

Maurois, André (1936): Lord Byron, Trad. Jorge Arnal, 2. ${ }^{a}$ ed., Madrid: Aguilar.

Orwell, George (2003): Orwell en España, Ed. Peter Davison, trad. Antonio Prometeo, Barcelona: Tusquets.

Rogers, F. Theo (1937): Spain: A Tragic Journey, Nueva York: The Macaulay Co.

Schaff, Adam (1978): "La concepción marxista del individuo", La concepción marxista del hombre, Madrid: Akal.

Skelton, Robin (ed.) (1964): Poetry of the Thirties, Harmondsworth: Penguin.

Spender, Stephen: The Destructive Element, Londres: Jonathan Cape, 219.

- (1937): Forward from Liberalism, Londres: Gollancz.

- (1939): The Still Centre, Londres: Faber \& Faber.

- $\quad$ (1940): Selected Poems, Londres: Faber \& Faber.

- (1951): World within a World. Londres: Hamish Hamilton.

- (1953): The Creative Element. Londres: Hamish Hamilton.
- $\quad$ (1955): Collected Poems. Londres: Faber \& Faber.

- $\quad$ (1963): The Struggle of the Modern. Londres: Hamish Hamilton.

- $\quad$ (1955): Selected Poems. Londres: Faber \& Faber.

- (1978): The Thirties and After. Nueva York: Random House.

- (1980): "Confessions and Autobiography", Autobiography: Essays Theoretical and Critical, Ed. James Olney, Princeton: Princeton University Press, 115-122.

- (1984): "From Poetry to Politics", Thirties Poets: "The Auden Group", Ed. Ronald Carter, Londres: MacMillan, 41-44.

- $\quad$ (1985): Collected Poems, Londres: Faber \& Faber.

- (1994): Dolphins, Londres: Faber \& Faber.

Sutherland, Jon (2004): Stephen Spender: The Authorized Biography, Londres: Viking.

Weatherhead, A. Kingsley (1975): Stephen Spender and the Thirties, Lewisburg: Bucknell University Press.

Wilson, Edmund (1996): El Castillo de Axel, Trad. Luis Maristany, Barcelona: Destino.

Woolf, Virginia (1985): Diary 5: 1936-41, Harmondsworth: Penguin.

Wordsworth, William (1994): Works, Ware: Wordsworth Editions.

Worsley, Cuthbert (1971): Fellow Travellers, Londres: London Magazine Editions. 